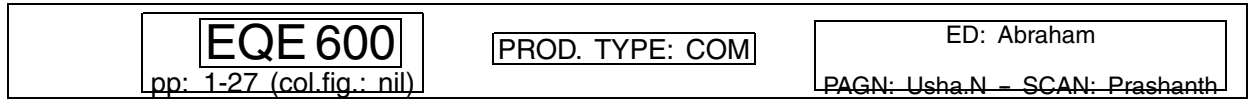

EARTHQUAKE ENGINEERING AND STRUCTURAL DYNAMICS

Earthquake Engng Struct. Dyn. 2006; 35:000-000

Published online in Wiley InterScience (www.interscience.wiley.com). DOI: 10.1002/eqe.600

\title{
Development and validation of a metallic haunch seismic retrofit solution for existing under-designed RC frame buildings
}

\author{
Stefano Pampanin ${ }^{1}$, Constantin Christopoulos ${ }^{2, *, \dagger}$ and Te-Hsiu Chen ${ }^{1}$ \\ ${ }^{1}$ Department of Civil Engineering, University of Canterbury, Christchurch, New Zealand \\ ${ }^{2}$ Department of Civil Engineering, University of Toronto, Canada
}

\section{SUMMARY}

The feasibility and efficiency of a seismic retrofit solution for existing reinforced concrete frame systems, designed before the introduction of modern seismic-oriented design codes in the mid 1970s, is conceptually presented and experimentally investigated. A diagonal metallic haunch system is introduced at the beam-

11 column connections to protect the joint panel zone from extensive damage and brittle shear mechanisms, while inverting the hierarchy of strength within the beam-column subassemblies and forming a plastic

13 hinge in the beam. A complete step-by-step design procedure is suggested for the proposed retrofit strategy to achieve the desired reversal of strength hierarchy. Analytical formulations of the internal force flow 15 at the beam-column-joint level are derived for the retrofitted joints. The study is particularly focused on exterior beam-column joints, since it is recognized that they are the most vulnerable, due to their lack of

17 a reliable joint shear transfer mechanism. Results from an experimental program carried out to validate the concept and the design procedure are also presented. The program consisted of quasi-static cyclic tests

19 on four exterior, $\frac{2}{3}$ scaled, beam-column joint subassemblies, typical of pre-1970 construction practice using plain round bars with end-hooks, with limited joint transverse reinforcement and detailed without 21 capacity design considerations. The first (control specimen) emulated the as-built connection while the three others incorporated the proposed retrofitted configurations. The experimental results demonstrated 23 the effectiveness of the proposed solution for upgrading non-seismically designed RC frames and also confirmed the applicability of the proposed design procedure and of the analytical derivations. Copyright

25 (C) 2006 John Wiley \& Sons, Ltd.

Received 30 December 2005; Revised 14 May 2006; Accepted 15 May 2006

KEY WORDS: existing buildings; seismic retrofit; under-designed frames; haunch; shear hinge; beamcolumn joints

\footnotetext{
${ }^{*}$ Correspondence to: Constantin Christopoulos, Department of Civil Engineering, University of Canterbury, Christchurch, New Zealand.

†E-mail: c.christopoulos@utoronto.ca
}

Contract/grant sponsor: NZ Foundation of Science and Technology

Contract/grant sponsor: National Science and Engineering Research Council of Canada 


\section{EQE 600}

\section{INTRODUCTION}

Recent experimental investigations on the seismic performance of existing reinforced concrete 3 frame buildings, designed for gravity loads only, as typically found in seismic prone countries before the introduction of adequate seismic code provisions in the mid-1970s, have con-

5 firmed the expected inherent weaknesses of these systems [1-7], that have been observed in past earthquake events. Because of the poor detailing of the reinforcement, the absence of ca-

7 pacity design philosophy and the use of plain round reinforcing bars, undesirable brittle failure mechanisms are observed at either the local level (i.e. shear failures in joints, beam or col-

9 umn members) or globally in the structure (i.e. soft-storey mechanisms). The beam-column joint panel region is of particular interest in such systems, as it is likely to be the critical

11 and possibly the weakest link according to capacity design or hierarchy of strength considerations. Joint damage and failure can in fact lead to severe deterioration of the overall lateral

13 load carrying capacity of the structure and even result in total collapse. Appropriate retrofit strategies, capable of providing adequate protection to the joint region while modifying the

15 strength hierarchy between the different components of the beam-column connections, according to a capacity design philosophy, are thus required for improving the seismic response of such 17 structures.

Several strengthening/retrofit solutions have been studied in the past and have been adopted

19 in practical applications, ranging from conventional techniques (i.e. braces, jacketing or infills [8]) to more recent approaches including base isolation, supplemental damping devices or ad-

21 vanced non-metallic materials as fibre reinforced polymers (FRP) [9], or shape memory alloys (SMAs) [10]. Most of these retrofit techniques have evolved into viable upgrades of these

23 seismically deficient structures. However, issues of cost, invasiveness, and practical implementation still remain the most challenging aspects of retrofitting non-seismically designed RC

25 frames.

In this contribution, the feasibility and efficiency of a simple, low-invasive and cost-effective

27 retrofit solution, which relies on diagonal metallic haunches installed locally at the beam-column joints to protect the panel zone and to force a more desirable hierarchy of strength, is conceptually

29 presented, implemented and experimentally validated. Experimental results from quasi-static cyclic tests on four exterior beam-column subassemblies, at a $\frac{2}{3}$ scale, comprising of one as-built specimen

31 and three retrofitted solutions, confirmed the efficiency and reliability of the proposed retrofit solution and of the proposed design methodology.

\section{SEISMIC BEHAVIOUR OF POORLY DESIGNED RC FRAMES}

\subsection{Typical structural deficiencies of pre-1970s frame buildings}

35 As it has been widely reported in the literature [1,7], typical structural deficiencies of existing reinforced concrete frame systems are most often related to:

37 (a) Inadequate confining effects in the potential plastic hinge regions.

(b) Insufficient amount, if any, of transverse reinforcement in the joint regions.

39 (c) Low amount (nominal) of longitudinal and transverse reinforcement in columns and beams.

(d) Inadequate anchorage detailing (including end-hook solutions), for both longitudinal and transverse reinforcement. 
1 (e) Lapped splices of column reinforcement just above the floor level.

(f) Lower quality of materials (concrete and steel) when compared to current practice:

- plain round (smooth) bars for both longitudinal and transverse reinforcement;

- low-strength concrete.

5 The main variations between construction practices in different seismic-prone countries are related to the percentage of column longitudinal reinforcement, which strongly affects the beam-to-column

7 moment capacity ratio (increasing the tendency of developing soft-storey mechanisms), the different anchorage details in lap splice regions or within joint regions, as well as the minimum spacing of

9 the transverse reinforcement in beams and columns, affecting the shear capacity of the framing elements. Other observed differences are related to the use of shallow and wide beams (typical in

11 Mediterranean countries, abandoned in the late 1950s in NZ) instead of deeper beams, as well as to the type of slab (e.g. cast-in-situ versus lightweight hollow clay bricks).

\section{2.2. Vulnerability of the panel zone region}

As part of an extensive recent experimental and analytical research program on the seismic vulner-

15 ability of existing reinforced concrete frame buildings designed for gravity loads only, as typically found in Mediterranean countries before the introduction of seismic-oriented codes in the mid-

17 1970s, a series of quasi-static cyclic tests on $\frac{2}{3}$ scaled beam-column joint subassemblies (interior and exterior) as well as on two three-storey three-bay frame systems, prior to and after retrofit

19 using FRP solutions, have been carried out at the University of Pavia [6,7,11,12]. These tests confirmed and further highlighted the vulnerability of the panel zone region. Due to the absence

21 of capacity design considerations and the peculiar combination of plain round bars and end-hook anchorages, particularly brittle joint shear damage mechanisms were observed and are expected

23 in exterior beam-column joints (see Figure 1), with the development of a joint shear mechanism before the occurrence of any flexural hinging in the beam (or more likely in the column). At a

25 global system level, these local damage mechanisms (including column hinging in interior beamcolumn joint) could result in rapid strength deterioration of the lateral load carrying system, low levels of displacement ductility as well as soft-storey mechanisms.
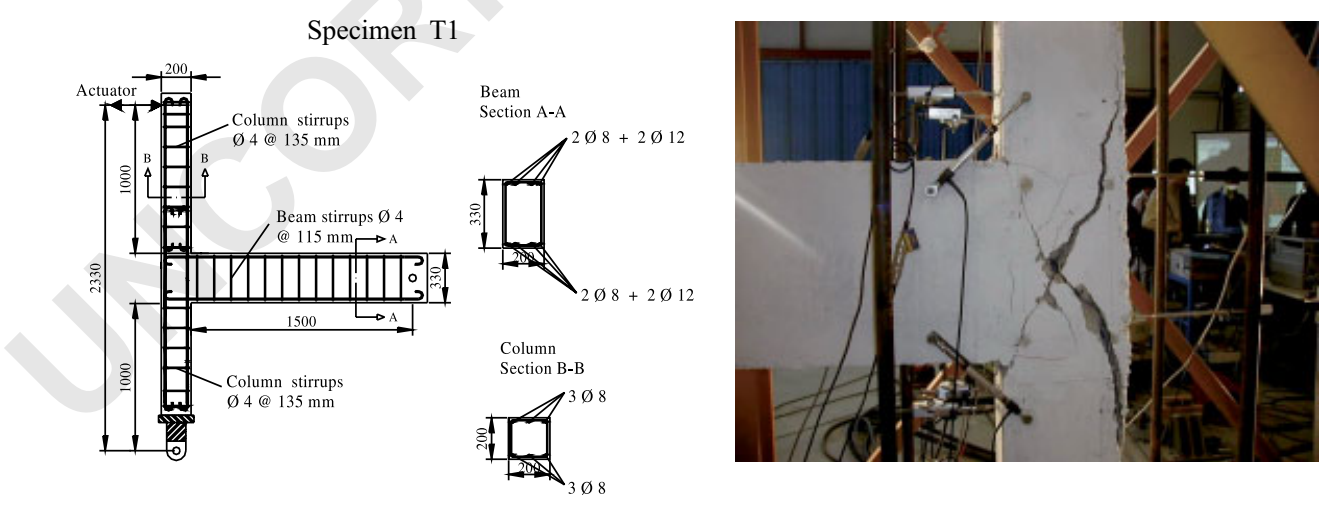

Figure 1. Typical geometry and reinforcement details of a pre-1970 beam column and experimental joint shear failure mechanism [6]. 


\section{EQE 600}

Different damage or failure modes are expected to occur in non-seismically designed beamcolumn joints $[6,13]$ depending on the typology (exterior or interior joint) and on the detailing (i.e.

3 amount, if any, of transverse reinforcement in the joint; use of plain round or deformed bars; bar anchorage detailing). In absence of transverse reinforcement in the joint region, the post-cracking

5 behaviour depends solely on the efficiency of the compression strut mechanism to transfer the shear within the joint. Thus, while rapid joint strength degradation after joint diagonal cracking is

7 expected in exterior joints, a hardening behaviour after first diagonal cracking is usually observed for interior joints [13]. On the other hand, the concentration of shear deformation in the joint region,

9 through the activation of a shear hinge mechanism [13], can reduce the deformation demand on adjacent structural members, postponing the occurrence of undesirable soft-storey mechanisms

11 which can lead to the collapse of the entire structure. A critical discussion on the effects of damage and failure of beam-column joint (panel zone) in the seismic assessment of frame systems

13 can be found in Reference [11].

With the original intent to develop a comprehensive database for the characterization and

15 modelling of the joint panel zone shear damage mechanism, further experimental investigations have been carried out and are ongoing at the University of Canterbury in New Zealand. These tests

17 include quasi-static uni- and bi-directional loading on exterior beam-column joint subassemblies with different structural details (either plain round or deformed bars, without stirrups or with a

19 single horizontal stirrup in the joint, deep beam or shallow-wide beam) [14]. One of the tested pre-1970s as-built solutions has been selected in this study as a benchmark or control specimen

21 for the retrofit solution and is discussed in more detail in the following paragraphs. The extensive analytical and numerical modelling of existing non-seismically designed RC frames is beyond the

23 scope of this paper. The readers are referred to References $[13,15,16]$ for recent overviews of different analytical procedures reported in the literature.

\section{RETROFIT SOLUTION USING A DIAGONAL HAUNCH SYSTEM}

\subsection{Conceptual challenges and retrofit strategy}

27 A retrofit solution for existing under-designed $\mathrm{RC}$ frame systems is herein proposed as an extension of the haunch retrofit solution developed for steel moment resisting frames following the significant

29 number of weld fractures observed after the Northridge earthquake [17-19]. It is worth underlining that the main scope of the haunch retrofit solution, as originally proposed for moment resisting steel

31 frames, was primarily to relocate the plastic hinge away from the welded connection to protect the welds from premature cracking. These moment-resisting steel frame systems were already

33 typically designed according to capacity design considerations, thus prone to develop hinging in the beams (weak-beam/strong column system) if the welds were adequately protected.

35 When applying this retrofit solution to existing reinforced concrete frame buildings designed without capacity design considerations, additional challenges arise since it is not guaranteed that

37 the desired beam flexural hinging mechanism will develop even if the panel zone is adequately protected. The primary aim of the proposed seismic retrofit strategy is thus to eliminate the

39 damage in the beam-to-column panel zones while enhancing the global response of non-seismically designed RC frames by reversing the hierarchy of strength. Local haunch type elements, as

41 illustrated in Figure 2, are introduced in the vicinity of the beam-to-column connections to protect the panel zone region from excessive damage by re-directing the stress-flow around the joint region 

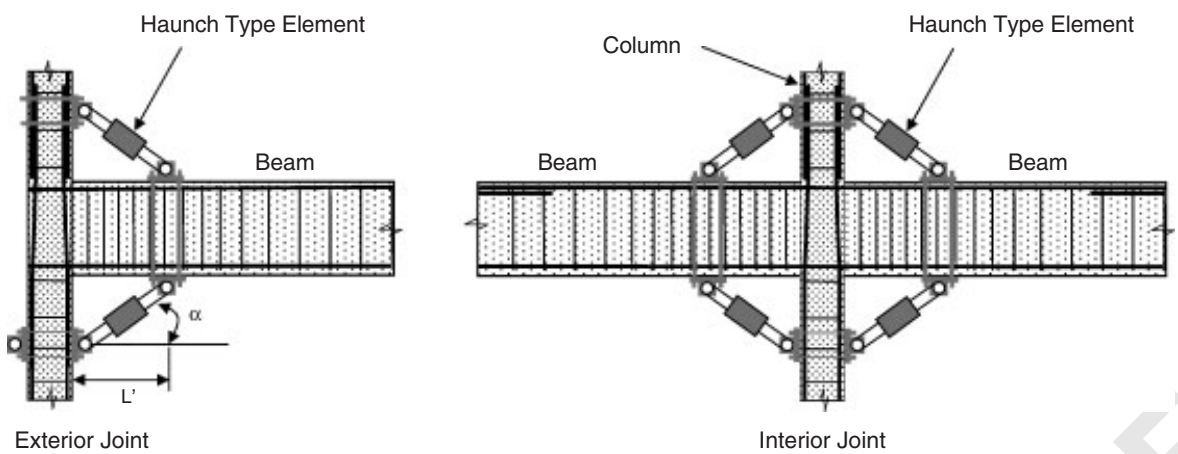

Figure 2. Proposed haunch retrofit configuration for exterior and interior joints.

1 and forcing the development of a relocated plastic hinge in the beam. The proposed steel haunch is used for both exterior and interior beam-to-column joints. The design of the retrofit consists of

3 properly selecting the geometry (distance from the column interface, $L^{\prime}$, and angle $\alpha$ ) as well as the axial stiffness $K_{d}$ of the haunch elements, such that the moment developed in the beam at

5 the face of the column is controlled, thus protecting the joint panel zone from undesirable brittle failure mechanisms. Furthermore, the design must also assure the reversal of the strength hierarchy

7 by forcing a flexural plastic hinge in the beam close to the location where the haunch is connected. It is intended, through capacity design considerations, that shear failure mechanisms be avoided

9 in both beams and columns when the relocated flexural hinges are formed in the beams.

As proposed by Christopoulos and Filiatrault [19], based on numerical investigations on steel

11 moment resisting frames, the haunch type elements can also be designed as stiffening elements with sufficient strength to remain elastic under the applied loads, or as passive elasto-plastic devices

13 which rely either on hysteretic yielding or on friction type elements to provide supplemental damping to the system. Experimental implementation of both elastic and dissipating (through

15 yielding) haunch solutions are presented and discussed in the next paragraphs, based on the tests that were carried out on existing pre-1970 designed RC beam-column joints.

\section{3.2. Effect of haunch elements on internal forces at beam-column joint subassemblies}

When haunch type elements are introduced at a distance $L^{\prime}$ from the beam-column interface

19 and connected at an angle $\alpha$ above and below the beam (see Figure 2), the internal forces of the beam-column assembly are significantly altered. Figures 3 and 4 and the paragraph below

21 illustrate the effects of the haunch retrofit solution on moment and shear force diagrams in an exterior beam-column joint subassembly subjected to lateral loads (with inflexion points assumed

23 at mid-height of the column and mid-span of the beam). If designed adequately, the presence of the two haunches can significantly reduce the beam and column moments at the joint panel

25 zone interface. The maximum moment in the beam and in the column is relocated away from the original critical sections to the points where the haunches are connected. In particular, as discussed 27 in the following paragraphs, the migration of the maximum moment in the beam at a distance $L^{\prime}$ from the face of the column can be exploited to force a plastic hinge in the beam. It is of interest 29 to also note that a similar, though less efficient, reduction of internal forces at the joint level can be achieved by using a single haunch element, introduced only below (or above) the beam, in order 
Moment Diagrams

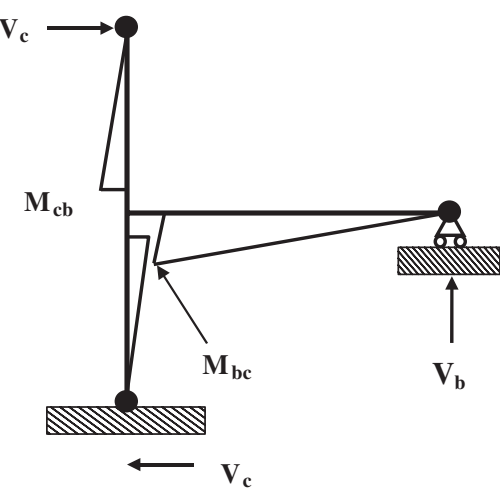

(a)

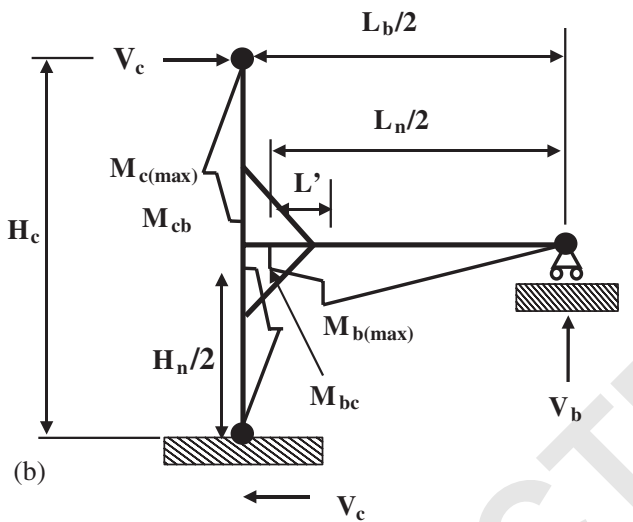

Shear Diagrams
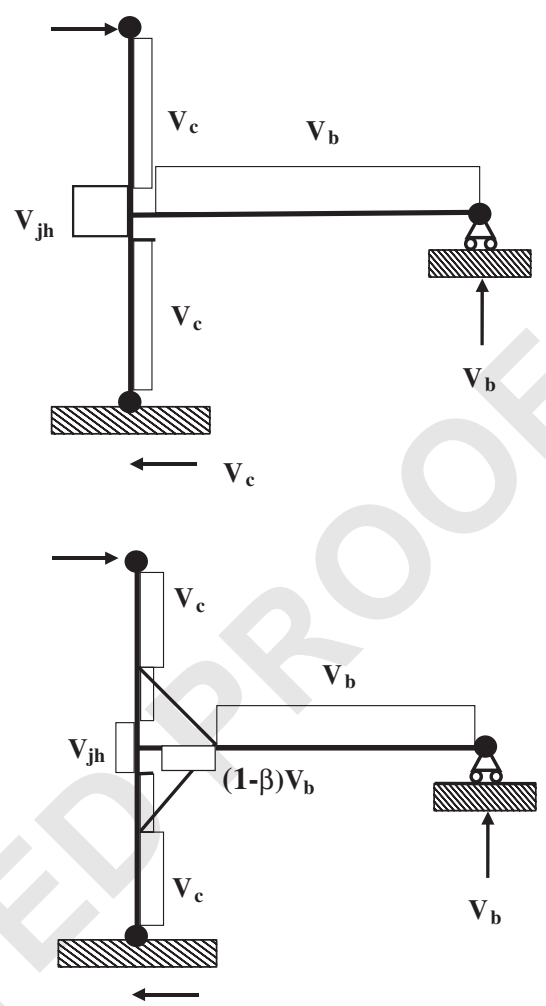

Figure 3. Moment and shear diagrams of exterior joint: (a) as-built solution; and (b) after retrofitting with two diagonal haunches.

1 to meet architectural requirement with an even less invasive retrofit intervention. The efficiency of the haunch intervention in modifying the internal shears and moments in the beams and columns

3 is dependent on the selection of the three haunch design parameters $L^{\prime}, \alpha$ and the axial stiffness of the haunch $K_{d}$. As illustrated in Figure 4, once the shear in the beam between the point of connection of the haunch (to the beam) and the face of the column $\beta V_{\mathrm{b}}$ is determined, the moment and shear diagrams from the point of inflexion to the face of the column are known. The factor

$7 \quad \beta$ is assumed to be known in the following expressions. The derivation of the factor $\beta$ based on displacement compatibility is discussed in detail in a subsequent paragraph. The beam moment at

9 the column interface, $M_{\mathrm{bc}}$, is thus given by

$$
M_{\mathrm{bc}}=M_{\mathrm{b}(\max )}-\Delta M_{H}-(1-\beta) V_{\mathrm{b}} L^{\prime}
$$

11 where $\Delta M_{H}=\left[\beta V_{\mathrm{b}}\left(d_{\mathrm{b}} / 2\right)\right] / \tan \alpha$ is the concentrated moment reduction at a distance $L^{\prime}$ from the face of the column (haunch location) due to the offset of the beam centreline from the point where

13 the haunches are connected to the beam (see Figure 2) and $d_{\mathrm{b}}$ is the depth of the beam. If the haunch-beam connection is done at mid-depth of the beam, this localized moment reduction would 


\section{EQE 600}

DEVELOPMENT OF METALLIC HAUNCH SEISMIC RETROFIT SOLUTION

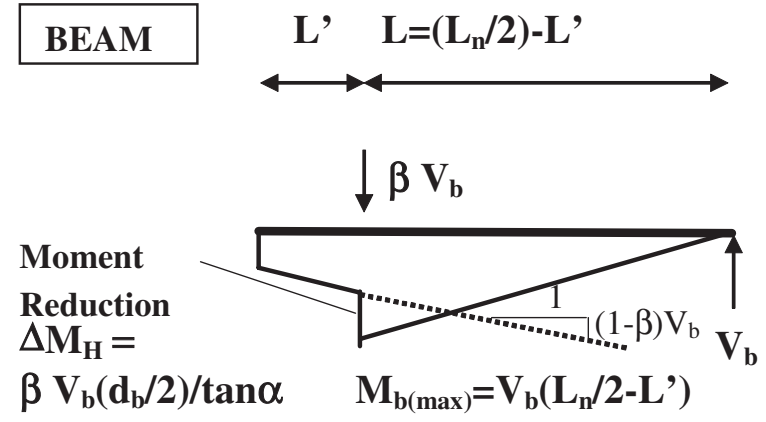

Moment Diagram

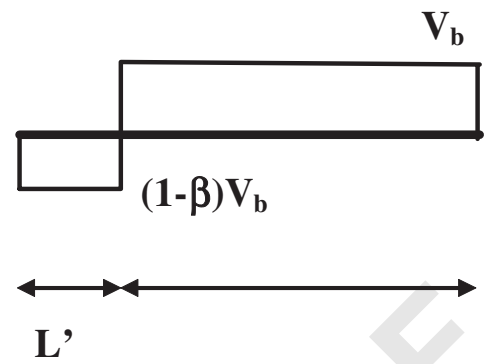

Shear Diagram

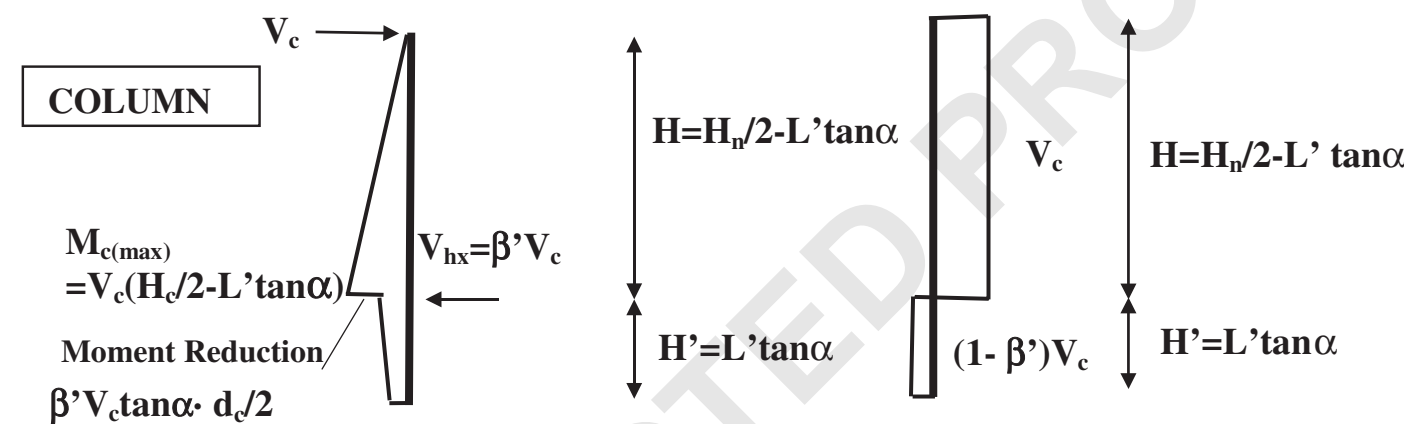

Moment Diagram

Shear Diagram

Figure 4. Moment and shear diagrams in the beam and column after retrofitting with two diagonal haunches.

1 not be present and is therefore not considered in the derivation of a general design procedure. As a result:

$$
M_{\mathrm{bc}}=M_{\mathrm{b}(\max )}\left[1-\frac{\beta d_{\mathrm{b}}}{2 L \tan \alpha}+\frac{(1-\beta) L^{\prime}}{L}\right]
$$

where $L=\left(L_{n} / 2\right)-L^{\prime}$ is the distance from the middle span of the beam to the location of the haunch with $L_{n}$ being the net beam span length (from face to face of columns).

Similarly, the reduction of the column moment at the beam interface can be expressed as

$$
M_{\mathrm{cb}}=M_{\mathrm{c}(\max )}\left[1-\frac{\beta^{\prime} d_{\mathrm{c}} \tan \alpha}{2 H}+\frac{\left(1-\beta^{\prime}\right) L^{\prime} \tan \alpha}{H}\right]
$$

where $H=\left(H_{n} / 2\right)-L^{\prime} \tan \alpha$ is the distance between the point of contraflexure at mid-height of

9 the column and the haunch location, $d_{\mathrm{c}}$ is the depth of the column and $\beta^{\prime}=\beta \cdot\left(H_{\mathrm{c}} / L_{\mathrm{b}} \tan \alpha\right)$ with $H_{\mathrm{c}}$ the total interstorey height (from centreline to centreline of beams), and $L_{\mathrm{b}}$ the total beam 


\section{EQE 600}

1 span length (from centreline-to-centreline of columns). The maximum column moment developed at the level of the haunch connection is therefore:

$$
M_{\mathrm{c}(\max )}=M_{\mathrm{b}(\max )} \frac{\left(H_{\mathrm{c}} / 2-d_{\mathrm{b}} / 2-L^{\prime} \tan \alpha\right)\left(1+\left(d_{\mathrm{c}}+2 L^{\prime}\right) /\left(L_{n}-2 L^{\prime}\right)\right)}{H_{\mathrm{c}}}
$$

or, alternatively

$$
M_{\mathrm{c}(\max )}=M_{\mathrm{b}(\max )} \frac{L_{\mathrm{b}} H}{L H_{\mathrm{c}}}
$$

\section{DESIGN PHILOSOPHY AND PROCEDURE}

\section{4.1. Protection of the panel zone and hierarchy of strength}

As discussed in the previous paragraphs, the proposed retrofit strategy aims to protect the panel

9 zone region while forcing a plastic flexural hinge in the beam at the location of the haunch connection. Capacity design considerations are derived to guarantee that a proper hierarchy of

11 strength is developed. When designing the haunch solution (choice of $L^{\prime}, \alpha$ and $K_{d}$ ), control of the actual hierarchy of strength can be obtained by imposing that the equivalent interstorey shear

13 corresponding to the development of a relocated plastic hinge in the beam at a distance $L^{\prime}$ from the face of the column is lower than those corresponding to undesirable critical mechanisms. These

15 mechanisms, from the least severe to the most severe on the overall integrity of the structure are: (i) column hinging, (ii) joint shear failure, (iii) beam shear failure, and (iv) column shear failure.

17 The global target hierarchy of strength of the whole design can be thus summarized as

$$
\bar{V}_{\mathrm{c}, \text { beam-hinge }} \leqslant \Phi_{1} \bar{V}_{\mathrm{c}, \text { col-hinge }} \leqslant \Phi_{2} \bar{V}_{\mathrm{c}, \text { joint }} \leqslant \Phi_{3} \bar{V}_{\mathrm{c}, \text { col-shear }} \leqslant \Phi_{4} \bar{V}_{\mathrm{c} \text {, beam-shear }}
$$

19 where $\Phi_{i}$ are safety factors separating two subsequent mechanisms.

\subsection{Step-by-step haunch design procedure}

21 The proposed design procedure consists of iterations on the properties defining the haunch system and is presented in the following steps:

23 Step 1: Preliminary choice of haunch properties. A preliminary selection of the properties of the haunches $L^{\prime}, \alpha$ and $K_{d}$ is first required. From a practical point of view, especially for frames

25 with weak column problems, starting with higher values of $\alpha$ will lead to a more effective retrofit and a quicker convergence to feasible solutions. Furthermore, to reduce the invasiveness of the

27 retrofit strategy, the lowest possible value of $L^{\prime}$ is preferred. The value of $K_{d}$ is also limited by the choice of the haunch element sections and materials. More than one combination of the haunch

29 properties may satisfy these requirements and it may be useful to investigate a number of possible combinations.

31 Step 2: Definition of acceptable damage/limit states in the joint. The starting point of the design scheme is to define the acceptable stress level in the joint, based on principle tensile stresses

$33 p_{\mathrm{t}}$ or principle compression stresses, $p_{\mathrm{c}}$, in the case of interior joints. As noted in the literature [20], principal stresses are more reliable than nominal shear stresses in capturing the response

35 of joints, since they consider the actual stress state of the joint given by a combination of the nominal shear force, $V_{j h}$ (or corresponding stress, $v_{j h}$ ) with the column axial load $(N)$. The 


\section{EQE 600}

DEVELOPMENT OF METALLIC HAUNCH SEISMIC RETROFIT SOLUTION

1 variation of column axial load during the lateral sway of a frame building can be quite significant, particularly in exterior beam-column joints, and should be properly accounted for when defining the

3 actual stress level. Strength degradation curves for existing beam-column joints based on principle tensile/compression stresses as a function of the joint shear deformation have been proposed in the

5 literature $[3,6,20]$. Values of the principal tensile stress of approximately $p_{\mathrm{t}}=0.2 \sqrt{f_{\mathrm{c}}^{\prime}}, f_{\mathrm{c}}^{\prime}$ being the concrete compression strength, have been for example proposed by Pampanin et al. [6] to

7 correspond to first cracking of exterior beam-column joints with plain round bars and end hooks. In a retrofitted configuration, the nominal (horizontal) shear force in the joint $V_{j h}$ can be expressed

9 as a function of the moment in the beam at the joint interface:

$$
V_{j h}=\frac{M_{\mathrm{bc}}}{j d_{\mathrm{b}}}-\left(V_{\mathrm{c}}-V_{h x}\right)
$$

11 where $j d_{\mathrm{b}}$ is the internal lever arm in the beam section between the tension and compression sides and $\left(V_{\mathrm{c}}-V_{h x}\right)$ or, $\left(1-\beta^{\prime}\right) V_{\mathrm{c}}$ is the actual shear value in the column at the panel zone interface

13 (see Figure 4) with $V_{h x}=\beta^{\prime} V_{\mathrm{c}}$ being the horizontal component of the haunch force acting on the column expressed by

$$
V_{h x}=\frac{2 \beta V_{\mathrm{c}} H_{\mathrm{c}}}{2 \tan \alpha\left(L_{n}+d_{\mathrm{c}}\right)}
$$

is the horizontal shear force introduced into the column from the haunch. By substituting

17 Equations (2) and (7) into Equation (6) and solving for $V_{\mathrm{c}}$, the interstorey shear corresponding to the occurrence of a defined level of shear or principle tensile stress demand (i.e. damage)

19 in the joint, herein referred to as $\bar{V}_{\mathrm{c}, \text { joint }}$, is given by

$$
\bar{V}_{\mathrm{c}, \text { joint }}=\frac{A_{\mathrm{e}} \sqrt{p_{\mathrm{t}}^{2}-\left(p_{\mathrm{t}} N / A_{\mathrm{g}}\right)}}{\left(1-\frac{\beta H_{\mathrm{c}}}{\left(L_{n}+d_{\mathrm{c}}\right) \tan \alpha}-\frac{H_{\mathrm{c}}\left(L_{n}-2 L^{\prime}\right)}{j d_{\mathrm{b}}\left(L_{n}+d_{\mathrm{c}}\right)}\left(1-\frac{\beta d_{\mathrm{b}}}{2 L \tan \alpha}+\frac{(1-\beta) L^{\prime}}{L}\right)\right)}
$$

21 where the numerator also represents the joint nominal shear force $V_{j h}=A_{\mathrm{e}} \sqrt{p_{\mathrm{t}}^{2}-\left(p_{\mathrm{t}} N / A_{\mathrm{g}}\right)}$ ( $A_{\mathrm{g}}$ being the column gross section and $A_{\mathrm{e}}$ the effective joint area).

23 Alternatively, a relationship between a given limit state in terms of joint shear and the beam moment at the joint interface, $\bar{M}_{\mathrm{bc}}\left(\right.$ or $\bar{M}_{j}$ ), can be written as

$$
\bar{V}_{\mathrm{c}, \text { joint }}=\frac{\bar{M}_{\mathrm{bc}} / j d_{\mathrm{b}}}{\left(2-\frac{2 \beta H_{\mathrm{c}}}{\left(L_{n}+d_{\mathrm{c}}\right) \tan \alpha}-\frac{H_{\mathrm{c}}\left(L_{n}-2 L^{\prime}\right)}{j d_{\mathrm{b}}\left(L_{n}+d_{\mathrm{c}}\right)}\left(1-\frac{\beta d_{\mathrm{b}}}{2 L \tan \alpha}+\frac{(1-\beta) L^{\prime}}{L}\right)\right)}
$$

Step 3: Force the development of a plastic hinge in the beam. The beam will hinge when the

27 maximum moment at the haunch connection $M_{\mathrm{b}(\max )}$ reaches the yielding moment capacity of the beam, $M_{\mathrm{b} y}$. The corresponding equivalent moment in the beam at the joint interface $M_{\mathrm{bc}}$ is

29 obtained simply by substituting $M_{\mathrm{b}(\max )}=\bar{M}_{\mathrm{b} y}$ into Equation (2). The equivalent interstorey shear (subassembly lateral force) corresponding to the development of a plastic hinge in the beam is 31 therefore given by

$$
\bar{V}_{\mathrm{c}, \text { beam-hinge }}=\bar{M}_{\mathrm{b} y} \frac{\left(1+\left(d_{\mathrm{c}}+2 L^{\prime}\right) /\left(L_{n}-2 L^{\prime}\right)\right)}{H_{\mathrm{c}}}
$$




\section{EQE 600}

1 In order to guarantee that the development of a plastic hinge in the beam occurs before a predefined level of damage is suffered by the joint, the following capacity design equation must be met:

$$
\bar{V}_{\mathrm{c}, \text { beam-hinge }} \leqslant \Phi_{1} \cdot \Phi_{2} \bar{V}_{\mathrm{c}, \text { joint }}
$$

Step 4: Check column is not hinging prior to beam or joint. It is important to recall that the development of the plastic hinge in the beam should also occur before the formation of a plastic hinge in the column at the location of the haunch (maximum moment $M_{\mathrm{c}(\max )}$ ). This hierarchy of strength can thus be guaranteed by ensuring that:

$$
\bar{V}_{\mathrm{c} \text {, beam-hinge }}<\Phi_{1} \bar{V}_{\mathrm{c}, \text { column-hinge }}<\Phi_{2} \bar{V}_{\mathrm{c}, \text { joint }}
$$

9 where $V_{\mathrm{c}, \text { col-hinge }}$ is the equivalent interstorey shear (subassembly lateral force) corresponding to the development of a plastic hinge in the column and given by:

$$
\bar{V}_{\mathrm{c}, \text { col-hinge }}=\frac{\bar{M}_{\mathrm{c} y}}{\left(H_{\mathrm{c}} / 2-d_{\mathrm{b}} / 2-L^{\prime} \tan \alpha\right)}
$$

where $\bar{M}_{\mathrm{c} y}$ is the yield moment of the column.

13 Step 5: Final check of shear capacity in members and control of global hierarchy of strength and sequence of events. The final check to meet the desired hierarchy of strength as expressed

15 in Equation (5) is achieved once the shear capacity of beam and column are checked against the shear demand that develops in each of these elements in the retrofitted configuration. It is worth

17 recalling that typical code provisions for either design or assessment (i.e. Reference [21]) suggest to neglect the concrete contribution when evaluating the shear capacity within a plastic hinge region

19 as for example in beams. Furthermore, when plain round bars are used, as typical of pre-1970s $\mathrm{RC}$ buildings, a main flexural crack is expected to develop directly at the critical interface and

21 progressively widen due the premature loss of bond properties and slip of the bars, as confirmed by a large number of experimental investigations carried out by numerous researchers on effects of plain

23 round bars (e.g. Reference [22]). In such conditions, different from the extensive cracking patterns typically observed when a plastic hinge forms over a certain length, the efficiency of the beam

25 transverse reinforcement in carrying the internal shear forces can be substantially impaired. In such cases, dowel effects of the longitudinal bars are relied upon to transfer shear. To improve the shear transfer at this critical location, simple metallic corbels or shear keys can be incorporated into the system by extending the connection plates of the haunch at the beam level a few centimeters towards

29 the middle of the beam. In the validation experiments presented in the following paragraphs, no shear keys (corbels) were used to demonstrate that the dowel effect is sufficient in transferring the 31 beam shear.

Iteration process: The iteration process consists of redefining the haunch properties (step 1) 33 every time either one of steps $2-4$ are not satisfied. The above steps can easily be programmed into a spreadsheet for rapid use by designers. If certain parameters of the system make it unfeasible

35 for all the steps to be met, alternative solutions can be combined with the proposed haunch to meet the design requirements. Due to wide differences in the spacing of the transverse reinforcement

37 in different regions of the world (due to different minimum requirements in codes or by-laws in the 1950-1970s, as well as different construction practices from country to country), in some

39 cases the shear capacity of an existing under-designed column or beam (at a section away from the column interface) is not sufficient to guarantee a proper inversion of the hierarchy of strength 41 with the formation of the desired flexural hinge in the beam. As further discussed in Section 5.6, 


\section{EQE 600}

DEVELOPMENT OF METALLIC HAUNCH SEISMIC RETROFIT SOLUTION

1 although columns were originally not designed for the increased shear demands associated with the introduction of the haunch elements their reserve shear capacity is usually adequate to carry

3 this additional shear. In such cases, a simple hybrid retrofit solution could be adopted whereby the haunch retrofit intervention is combined with other means of protecting the structural elements

5 from shear failure. Composite materials (FRP) in the form of strips, sheets, or rods as well as other forms of local jacketing (i.e. steel plates) could be for example adopted. Such additional

7 interventions could also improve the flexural strength of the column, while still allowing for an intervention that is overall less invasive than most of traditional retrofits where retrofit of the joint

9 panel zone causes major disruption of the floor system around the column. Similarly, vertical post-tensioned bars or externally mounted surface could be adopted to increase the shear (as well

11 as flexural) capacity of the column (as well as of the joint).

\subsection{Evaluation of the $\beta$-factor to account for deformation compatibility}

13 As illustrated in Figure 4 and in the aforementioned equations, the $\beta$-factor is a critical design parameter. Once evaluated, it allows for the complete definition of moments and shears in beams

15 and columns and is therefore critical in the definition and design of the proposed retrofit solution.

The value of the $\beta$-factor can be determined by writing deformation compatibility equations

17 between the axial deformation of the haunch and the local deformations of beams and columns where the haunch is connected. The complete formulation of such an equation involves axial,

19 flexural and shear deformations in both beams and columns as well as panel zone elastic shear deformations. However, depending on the relative stiffness of elements and the relative contribution

21 of these deformations to the total local deformation, simpler equations neglecting some of these contributions can be derived. A first derivation of the $\beta$-factor has been proposed by Yu $e t$ al.

23 [17] in the formulation of a (single) haunch retrofit solution for steel frame buildings, which for simplicity accounts only for the beam flexural deformations. Adapting this equation to the

25 configuration proposed in this paper (shown in Figures 2 and 3), the following expression can be derived:

$$
\beta=L^{\prime}\left(\frac{-6 L d_{\mathrm{b}} \sin \alpha \cos \alpha-3 L^{\prime} d_{\mathrm{b}} \sin \alpha \cos \alpha-6 L^{\prime} L+6 L^{\prime} L \cos ^{2} \alpha-4 L^{\prime 2}+4 L^{\prime 2} \cos ^{2} \alpha}{-3 \cos ^{2} \alpha d_{\mathrm{b}}^{2} L^{\prime}-6 d_{\mathrm{b}} L^{\prime 2} \sin \alpha \cos \alpha-4 L^{\prime 3} \cos ^{2} \alpha-12 E I_{\mathrm{b}} /\left(2 K_{d}\right)}\right)
$$

where $I_{\mathrm{b}}$ is the moment of inertia of the beam and $K_{d}$ is the axial stiffness of one haunch element. A simpler expression can be obtained by substituting $a=L^{\prime}$ and $b=L^{\prime} \tan \alpha$ :

$$
\beta=\left(\frac{b}{a}\right) \cdot \frac{6 L d_{\mathrm{b}}+3 a d_{\mathrm{b}}+6 b L+4 a b}{3 d_{\mathrm{b}}^{2}+6 b d_{\mathrm{b}}+4 b^{2}+\left(12 E I_{\mathrm{b}} / 2 K_{d} a \cos ^{2} \alpha\right)}
$$

31 Considering the moment diagram presented in Figure 4, it can be seen that values of $\beta$ greater than 1 are desirable for a more efficient protection of the beam-to-column joint. For given properties

33 of beam and column sections, a number of combinations of $L^{\prime}, \alpha$ and $K_{d}$ are possible such that the final design solution can limit the invasiveness of the added haunch elements while providing

35 the necessary or targeted upgrade to the system. As a general rule, larger values of $\beta$ reduce the effect of the haunches on the maximum moments in the columns and are therefore preferred for

37 cases where weak-column behaviour is expected. However, in order to avoid excessive increase of shear demands in the beam and column elements, $\beta$ should generally not exceed a value of 2 . 


\section{EQE 600}

\subsection{Refinement of deformation compatibility equation to account for column deformation}

As will be further discussed in the following paragraphs, a conservative design was followed in

the first phase of the experimental project using the original formulation of the $\beta$-factor which neglects column and joint deformability (Equations (14) or (15)). The first experimental results (presented in subsequent paragraphs) highlighted the inaccuracy of such a formulation which neglects deformations in the column. Although this equation was adequate for steel moment resisting frames where column deformations are smaller, for existing pre-1970s frame systems where columns were designed only considering gravity loads, these deformations are significant.

Two more refined versions of the $\beta$-formulation were therefore derived to also account for: (i) the column flexibility and (ii) the column and joint flexibility. Equation (16) shows the formula-

11 tion of the $\beta$-factor when including column flexibility in addition to beam flexibility. The additional terms (when compared to Equation (15)) related to the column flexibility are highlighted in boxes:

$$
\beta=\left(\frac{b}{a}\right) \cdot \frac{6 L d_{\mathrm{b}}+3 a d_{\mathrm{b}}+6 b L+4 a b+\sqrt{\frac{2 I_{\mathrm{b}} L_{\mathrm{b}} b^{3}}{I_{\mathrm{c}} a H_{\mathrm{c}}}+\frac{3 I_{\mathrm{b}} H L_{\mathrm{b}} b^{2}}{I_{\mathrm{c}} a H_{\mathrm{c}}}+\frac{3 I_{\mathrm{b}} d_{\mathrm{c}} L_{\mathrm{b}} b^{3}}{2 I_{\mathrm{c}} a^{2} H_{\mathrm{c}}}+\frac{3 I_{\mathrm{b}} d_{\mathrm{c}} H L_{\mathrm{b}} b^{2}}{I_{\mathrm{c}} a^{2} H_{\mathrm{c}}}}}{3 d_{\mathrm{b}}^{2}+6 b d_{\mathrm{b}}+4 b^{2}+\frac{12 E I_{\mathrm{b}}}{\left(2 K_{d} a \cos ^{2} \alpha\right)}+\frac{6 I_{\mathrm{b}} b^{2}}{a^{2} A_{\mathrm{c}}}+\frac{2 I_{\mathrm{b}} b^{3}}{I_{\mathrm{c}} a}+\frac{3 I_{\mathrm{b}} d_{\mathrm{c}} b^{2}}{I_{\mathrm{c}} a^{2}}+\frac{3 I_{\mathrm{b}} d_{\mathrm{c}}^{2} b^{3}}{2 I_{\mathrm{c}} a^{3}}}
$$

13 where $A_{\mathrm{c}}$ and $I_{\mathrm{c}}$ are, respectively, the gross-section area and the moment of inertia of the column. When the joint flexibility is also included, the complete formulation of the $\beta$-factor is given by

15 Equation (17), where the separate contribution from the beam (terms with no brackets), column (terms in [] brackets) and joint deformations (terms in \{\} parentheses) are indicated in the numerator 17 and denominator:

$$
\begin{aligned}
\beta=\left(\frac{b}{a}\right) \cdot \frac{6 L d_{\mathrm{b}}}{a}+3 a d_{\mathrm{b}}+6 b L+4 a b+\frac{2 \frac{2 I_{\mathrm{b}} L_{\mathrm{b}} b^{3}}{I_{\mathrm{c}} a H_{\mathrm{c}}}+\frac{3 I_{\mathrm{b}} H L_{\mathrm{b}} b^{2}}{I_{\mathrm{c}} a H_{\mathrm{c}}}+\frac{3 I_{\mathrm{b}} d_{\mathrm{c}} L_{\mathrm{b}} b^{3}}{2 I_{\mathrm{c}} a^{2} H_{\mathrm{c}}}+\frac{3 I_{\mathrm{b}} d_{\mathrm{c}} H L_{\mathrm{b}} b^{2}}{I_{\mathrm{c}} a^{2} H_{\mathrm{c}}}}{\left.\left.3 d_{\mathrm{b}}^{2}+6 b d_{\mathrm{b}}+4 b^{2}+\frac{12 E I_{\mathrm{b}}}{\left(2 K_{d} a \cos ^{2} \alpha\right)}+\frac{d_{\mathrm{b}}}{2}\right)\left(a+\frac{d_{\mathrm{c}}}{2}+L\right)\right\}} \\
+\left\{\frac{12 E I_{\mathrm{b}} b}{a^{2} A_{\mathrm{c}}}+\frac{2 I_{\mathrm{b}} b^{3}}{I_{\mathrm{c}} a}+\frac{3 I_{\mathrm{b}} d_{\mathrm{c}} b^{2}}{I_{\mathrm{c}} a^{2}}+\frac{3 I_{\mathrm{b}} d_{\mathrm{c}}^{2} b^{3}}{2 I_{\mathrm{c}} a^{3}}\right. \\
\left.+\left(b+\frac{d_{\mathrm{c}}}{2}\right)\left(1+\frac{d_{\mathrm{b}}}{2 b}+\frac{d_{\mathrm{c}}}{2 a}\right)\right\}
\end{aligned}
$$

19 Details on the full derivation of the $\beta$-factor to account for beam, column and joint flexibilities can be found in Reference [23]. A comparison between the different formulations of the $\beta$-factor

21 (Equations (15)-(17)) are shown in Figure 5. Theoretical predictions using Equations (15)-(17) are shown in the form of design charts and compared with numerical results from SAP2000, where

23 elastic frame models have been used to represent the retrofitted beam-column joint. It is interesting to note that the values of $\beta$ evaluated from a beam-only-flexibility tend to be lower (up to 15-20\%) 


\section{EQE 600}

DEVELOPMENT OF METALLIC HAUNCH SEISMIC RETROFIT SOLUTION
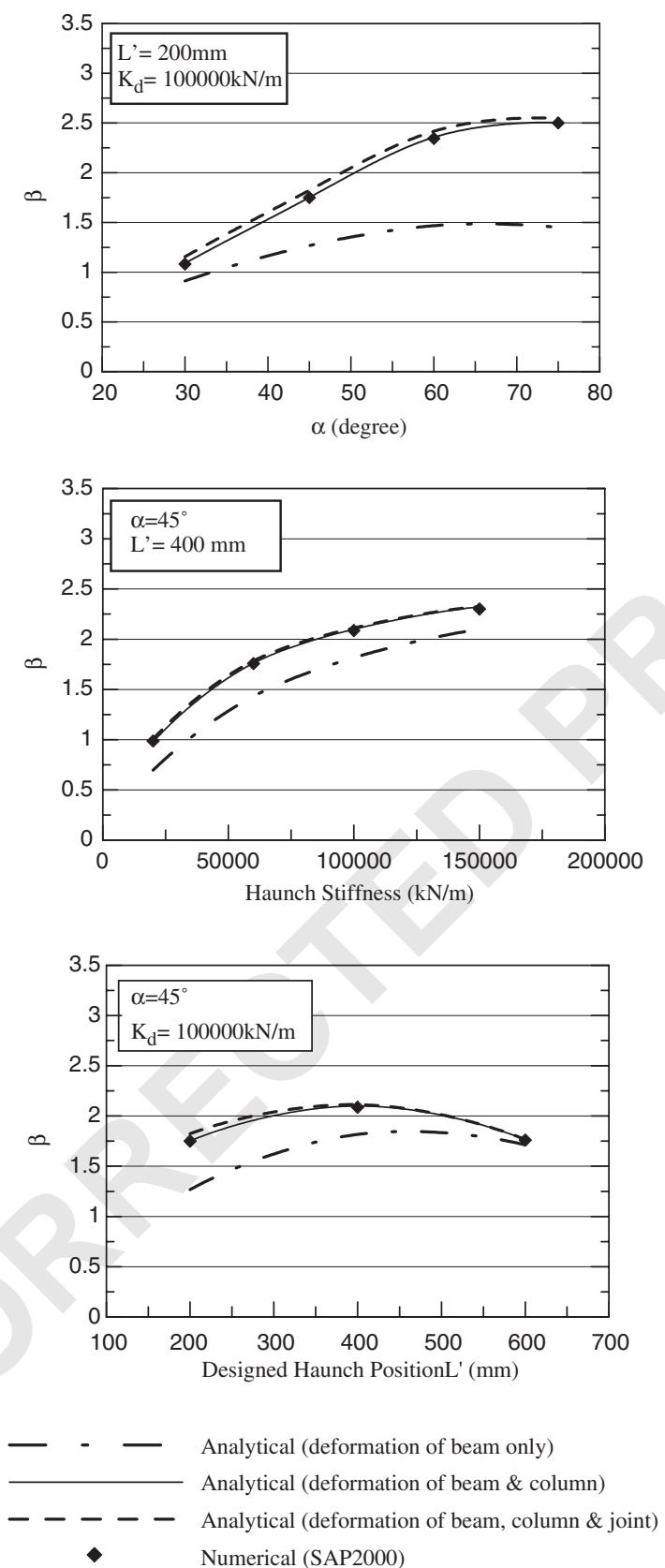

Figure 5. Comparison between alternative formulations of the haunch $\beta$-factor when accounting for deformation contribution of beam, column and/or joint elements. 


\section{EQE 600}

1 than the corresponding values calculated including the column deformability, thus underestimating the efficiency of the added haunch in protecting the panel zone (conservative) as well as the shear

3 forces developed in the structural elements (unconservative). The values obtained when including the column or the column and joint deformability were very close to the values obtained using the

5 SAP2000 model. It can also be seen in Figure 5 that when the column deformations are included, neglecting the joint deformations has a small impact on the predicted values of the $\beta$-factor.

\section{4.5. Multi-level retrofit strategies to control the global behaviour}

The retrofit strategy outlined thus far has been focused on the local (subassembly) level, assuming

9 that in a real design situation, all interior and exterior joints would be retrofitted. According to a multi-level retrofit strategy approach $[12,24]$, two levels of retrofits can be adopted when

11 considering the global response of the frame: (i) a complete retrofit would consist of a full upgrade by protecting all joint panel zones and developing plastic hinges in beams while columns

13 are protected according to capacity design principles, and (ii) a partial retrofit would consist of protecting exterior joints (which are the most vulnerable), forming plastic hinges in beams framing

15 into exterior columns, while allowing for column hinging and minor joint cracking in interior joints due to their more stable behaviour with hardening after first cracking.

\section{4.6. Preliminary numerical investigations and feasibility studies}

Preliminary numerical investigations and feasibility studies on the efficiency of the proposed 19 complete and partial retrofit solutions were presented by Pampanin and Christopoulos [24]. It is worth recalling that when assessing the seismic performance of existing pre-1970s buildings)

21 under-designed or designed-for-gravity-only buildings via numerical/analytical investigations, an adequate modelling of the complex inelastic behaviour of the whole frame system, including the

23 joint panel zone is a complex but essential task $[13,15,16]$. In particular, alternative approaches for modelling the RC beam-column joint, ranging from simplified empirical or macro-models

25 (single- or multi-spring models) to refined finite elements models, are available in literature and under continuous development and validation with experimental results. A detail discussion on the

27 topic is out of the scope of this contribution. Recent proposals including overviews and summary of available methods/models can be found in References [13, 16]. Comparative performance of

29 beam-column joints as well as multi-storey frames for as-built (pre-1970s design) and for retrofitted configurations were carried out through either push-pull (cyclic) or non-linear time-history nu-

31 merical analyses. Numerical results based on the aforementioned lumped plasticity model [13] confirmed the feasibility and high efficiency of the overall retrofit strategy in protecting the panel

33 zone (as well as the other structural elements) from shear damage or failure, inverting the hierarchy

35 of strength by changing the load path and developing stable plastic hinges in the beams. The overall seismic response of the retrofitted frames was also significantly enhanced.

\section{IMPLEMENTATION AND EXPERIMENTAL VALIDATION OF THE RETROFIT SOLUTION}

\subsection{Experimental program}

39 A series of experimental tests on $\frac{2}{3}$ scaled exterior beam-column joints, in a 2-D configuration, for different details for the haunch systems have been carried out in the Structural Laboratory of 
1 the University of Canterbury to verify the constructability and efficiency of the proposed solution and to validate the design procedure.

3 Experimental results from quasi-static tests on three exterior beam-column joints (specimens THR1, THR2, THR3) are herein reported and critically discussed by comparing the observed

5 damage and performance of a benchmark (as-built) specimen, TDP2, representative of general construction practice in the 1950s and 1960s in most of seismic prone counties and tested as part

7 of a more comprehensive research investigation on the seismic behaviour of under-designed beamcolumn joints with alternative structural details in the panel zone region [14]. Figure 6 and Table I

9 show the specimen geometric properties and reinforcement details. Plain round bars (Grade 300) with end hook anchorage and one single stirrup in the joint panel zone. It is worth recalling that the

11 overall scope of the research investigation was in fact to implement and validate the efficiency of a general retrofit solution for under-designed buildings (regardless of the aforementioned differences

13 in structural detailing from country to country, which typically depends on national code provisions as well as on the local construction and design practice), able to protect the panel zone region

15 from a brittle shear failure mechanism, while targeting the inversion of the hierarchy of strength towards a weak-beam, strong column system. For such reasons, the structural details of the as-built

17 specimen were thus selected to generally represent older construction practice, where a typical brittle behaviour of the joint region would be expected in combination with high beam-to-column
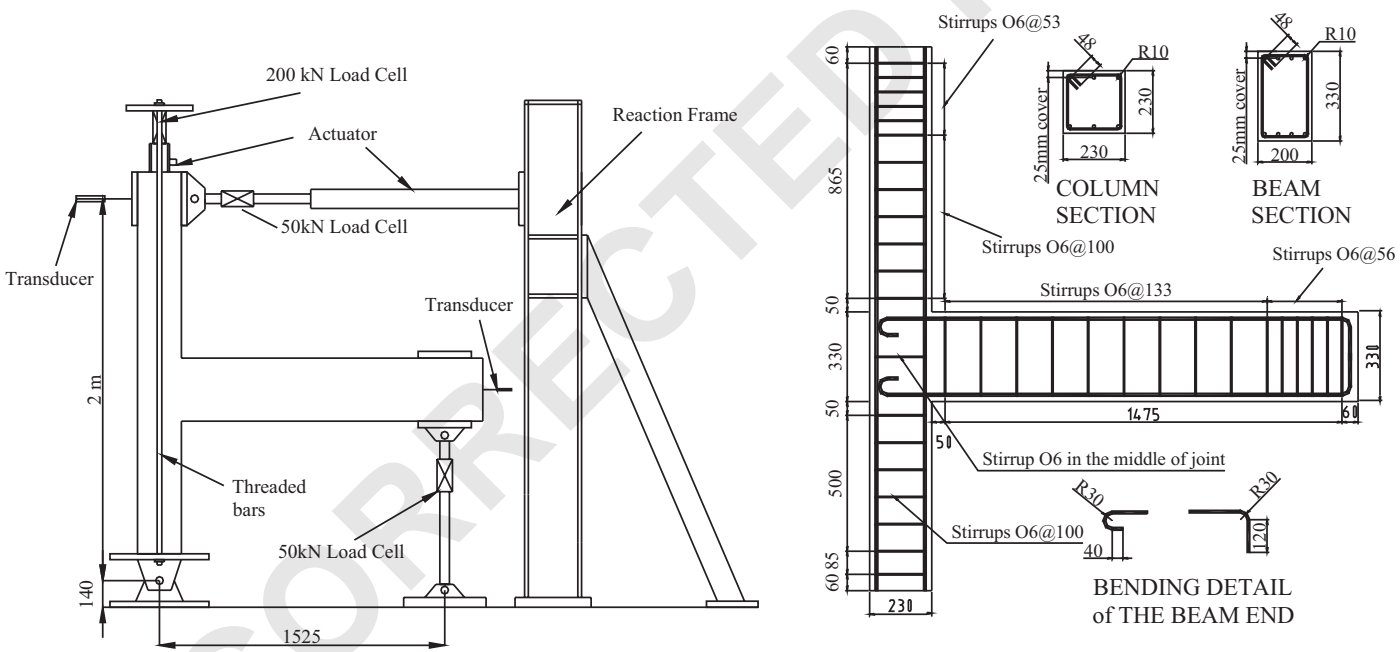

Figure 6. General test set-up and specimen properties.

Table I. Reinforcement properties of specimens.

\begin{tabular}{lcc}
\hline & $\begin{array}{c}\text { Longitudinal } \\
\text { reinforcement }\end{array}$ & $\begin{array}{c}\text { Transverse } \\
\text { reinforcement }\end{array}$ \\
\hline Beam $(200 \times 330 \mathrm{~mm})$ & $4+4 \mathrm{R} 10$ & R6@133 mm \\
Column $(230 \times 230 \mathrm{~mm})$ & $3+3 \mathrm{R} 10$ & R6@100 mm (one in joint) \\
\hline
\end{tabular}


Table II. Concrete compression strength.

\begin{tabular}{lcc}
\hline Specimen & $\begin{array}{c}f_{c}^{\prime} \text { at } 28 \text { days } \\
(\mathrm{MPa})\end{array}$ & $\begin{array}{c}f_{c}^{\prime} \text { at day } \\
\text { of testing }(\mathrm{MPa})\end{array}$ \\
\hline TDP2 & 21.3 & $23.3(50$ days $)$ \\
THR1 & 24.8 & 25.9 (56 days) \\
THR2 & 24.8 & $25.9(83$ days $)$ \\
THR3 & 22.1 & 26.8 (56 days) \\
\hline
\end{tabular}

Table III. Properties of reinforcing steel (Grade 300).

\begin{tabular}{lcccccc}
\hline Specimen & & Bar size $(\mathrm{mm})$ & $f_{y}(\mathrm{MPa})$ & $\varepsilon_{y}(\%)$ & $f_{u}(\mathrm{MPa})$ & $E$-modulus (GPa) \\
\hline TDP2 & Longitudinal & 10 & 333 & 0.15 & 467 & 219 \\
& Transverse & 6 & 408 & 0.21 & 482 & 191 \\
THR1 & Longitudinal & 10 & 344 & 0.15 & 478 & 228 \\
& Transverse & 6 & 396 & 0.2 & 485 & 198 \\
THR2 & Longitudinal & 10 & 341 & 0.156 & 480 & 218 \\
& Transverse & 6 & 396 & 0.2 & 485 & 198 \\
THR3 & Longitudinal & 10 & 347 & 0.158 & 474 & 219 \\
& Transverse & 6 & 352 & 0.157 & 436 & 224 \\
& & & & & & \\
\hline
\end{tabular}

1 moment capacity ratios to further challenge the inversion of the hierarchy of strength. Further discussion on the effects of alternative structural details in under-designed beam-column joints

3 on the local and global damage mechanism can be found in References [11,13,14] (Tables II and III).

\section{5.2. Test set-up and loading regime}

The quasi-static cyclic tests were carried out under an increasing level of lateral displacement

7 applied at the top of the column. The test set-up and loading protocol are shown in Figures 6 and 7. Beam and column elements were pinned at the assumed inflexion points (assumed to be

9 at mid-span of the beams and at mid-height of the columns). Simple supports at the beam ends were obtained connecting pin-ended steel members to the laboratory floor. Cyclic horizontal lateral

11 loading was applied to the top of the columns using a hydraulic actuator in displacement control. The lateral loading history consisted of a series of two cycles at increasing drift levels followed by

13 a small cycle at a $0.2 \%$ drift level. Furthermore, in order to reproduce the effects of a cyclic pushpull test on a frame system, the axial load in the column $F_{h}$ was varied during the experiments as

15 a function of the lateral load, according to a linear relationship derived from preliminary analyses on the prototype frame system (see Figure 7(b)). The varying axial load on the column represented

17 which affects column flexural capacity as well as joint shear capacity, allowed for a more realistic evaluation of the hierarchy of strength and sequence of mechanisms.

\section{5.3. Response of the as-built benchmark specimen TDP2}

The response of the as-built or benchmark specimen TDP2 (Figure 8) confirmed the weakness of 21 the beam-column joint panel zone observed in previous tests presented in the literature. First shear 

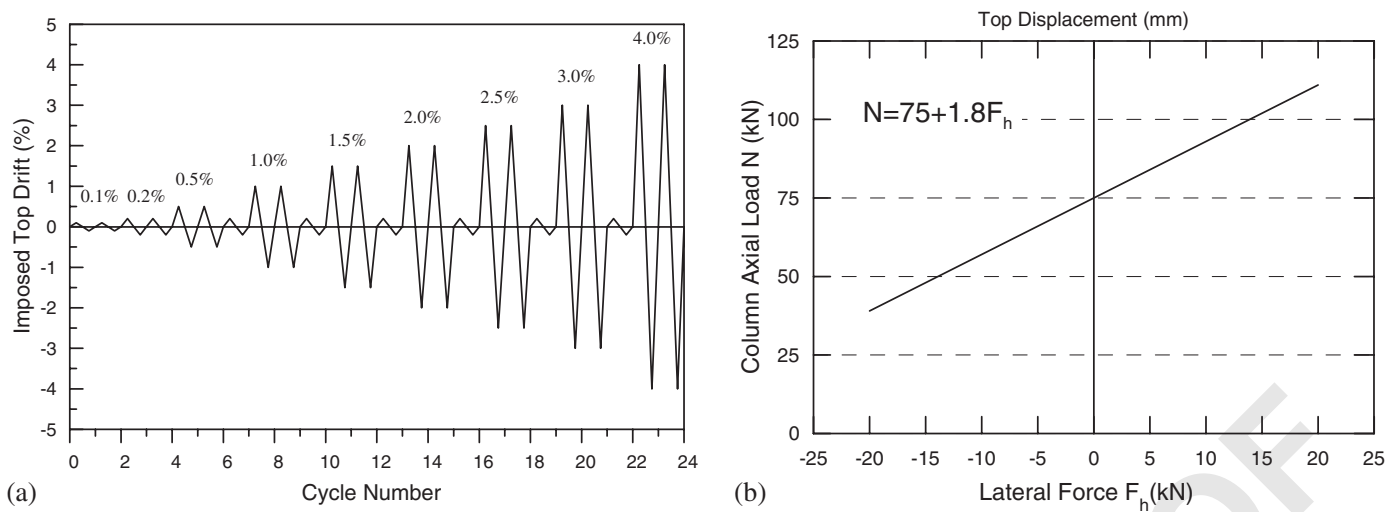

Figure 7. Loading history: (a) imposed lateral drift; and (b) variation of axial load with lateral force.
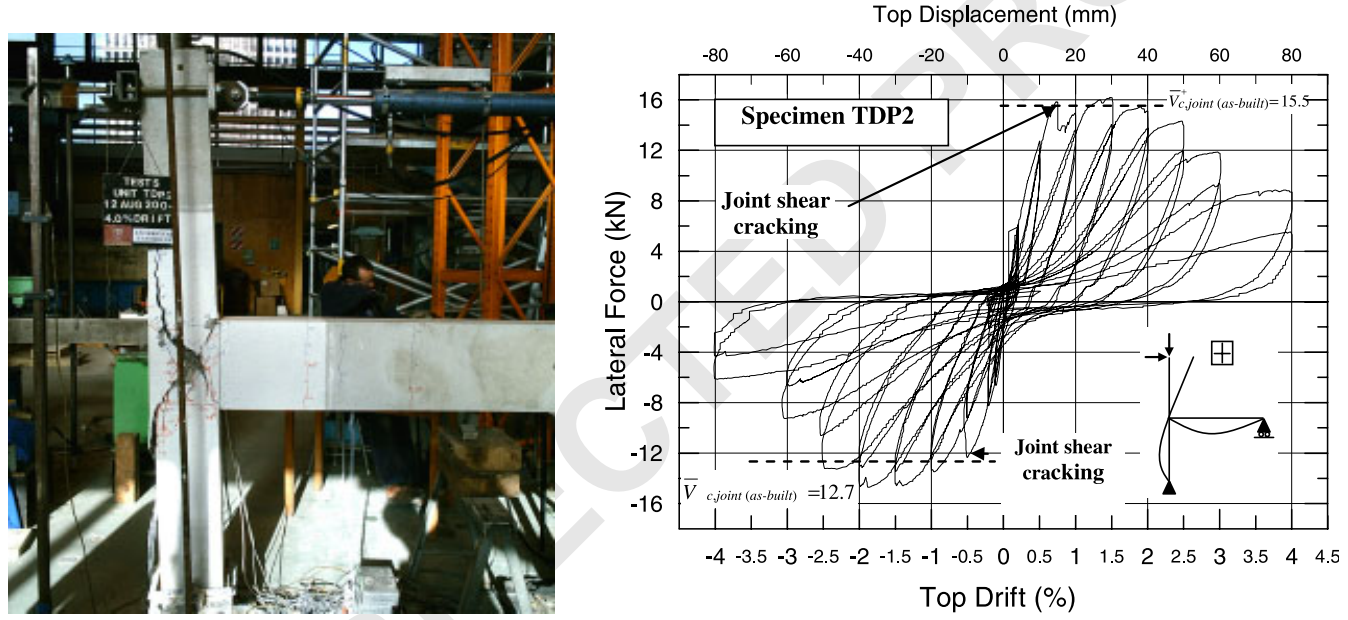

Figure 8. Global damage and hysteresis loop of the as-built specimen.

1 cracking in the joint region occurred at around $0.5 \%$ drift level followed by increased joint damage at increasing level of drift. No flexural damage occurred in the beams and columns. As a result

3 of the formation of a shear hinge mechanism, gradual loss of strength occurred beyond $1.5 \%$ drift with a marked pinching of the hysteretic curves (see Figure 8). It is worth noting that the presence

5 of one stirrup in the joint allowed for a more gradual reduction of strength when compared to the sudden and rapid degradation observed in previous tests with no transverse reinforcement at all in

7 the joint [6].

\subsection{Design of the haunch elements}

9 The design of the haunch retrofit solution system for all specimens was carried out following the conceptual procedure outlined in the previous paragraphs, with the intention of protecting 


\section{EQE 600}

1 the joint region from excessive damage while forcing a plastic hinge in the beam away from the column interface (at the outer side of the haunch connection). Beam and column members had

3 to also be protected against excessive shear demand and brittle failure by controlling the haunch design parameters. Due to several uncertainties that were expected in the actual implementation

5 of the haunch device, the experimental testing and the specimen properties, a conservative design of the haunch device was followed in order to guarantee the desired hierarchy of strength while

7 maintaining proper 'margins' between critical events. As a result, assuming $L^{\prime}=400 \mathrm{~mm}$ and $\alpha=45^{\circ}$, the targeted design value for the haunch stiffness was $K_{d}=100000 \mathrm{kN} / \mathrm{m}$, corresponding

9 to 'actual' safety factors $\Phi_{1}$ and $\Phi_{2}$ of about 0.7 and 0.85 , respectively (see Table V).

The haunch system consisted of elastic elements for retrofitted specimens THR1 and THR3

11 and of a yielding fuse element for retrofitted specimen THR2. The haunches were connected to the concrete elements through either a hinged base for THR1 and THR2 or a welded base for

13 THR3. Two external rods, partially prestressed to guarantee proper anchorage of the whole haunch solution to the structural elements, were used, in addition to two anchors directly fastened to both

15 the beam and to the column (see Figure 9). The haunch axial element was obtained by machining down deformed bars for a designed length and then inserting them into steel grouted tubes adopted

17 as anti-buckling systems. The mechanical properties of the different haunch elements are summarized in Table IV. It is worth noting that the expected equivalent stiffness $\left(K_{d} \cong 100000 \mathrm{kN} / \mathrm{m}\right)$
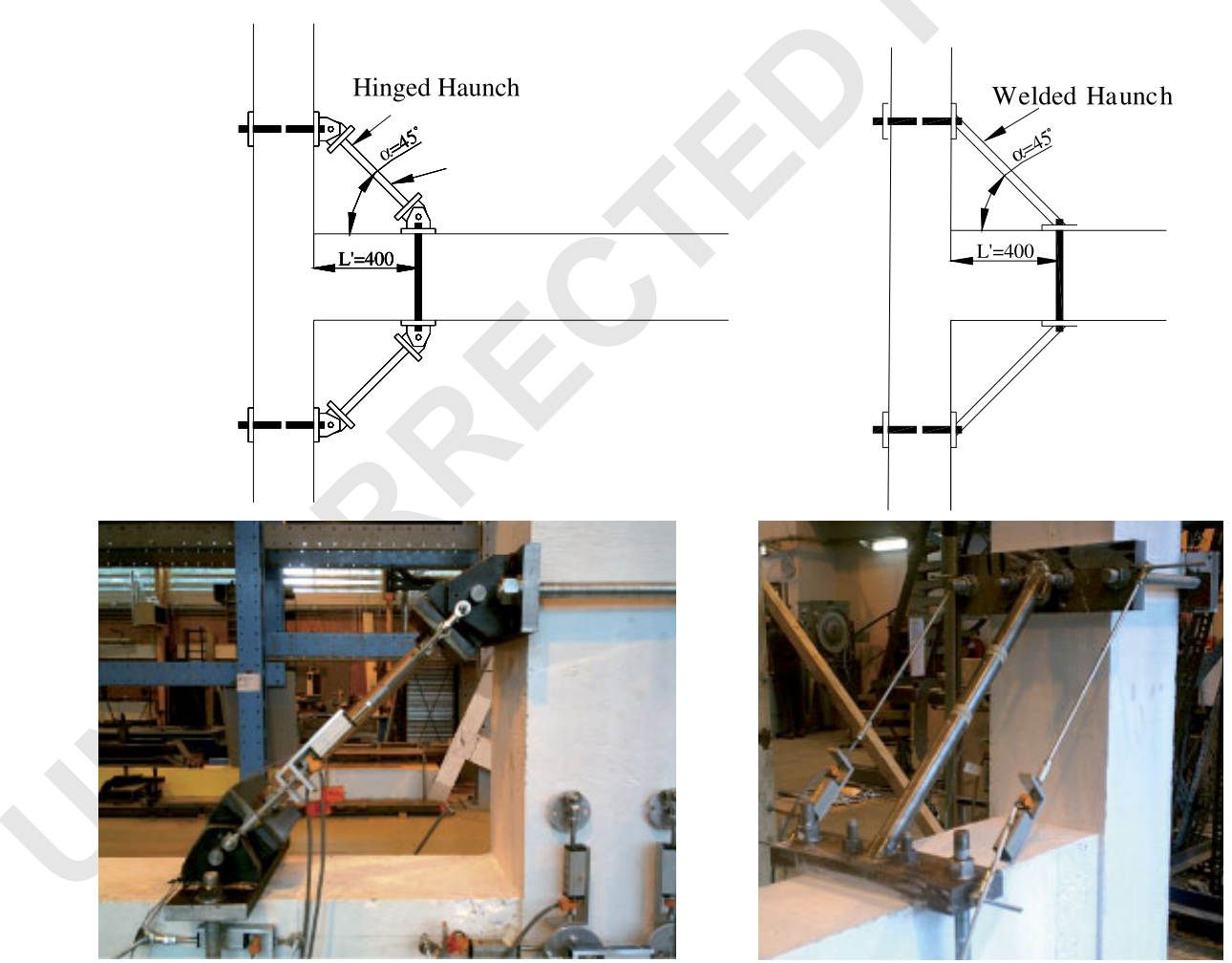

Figure 9. Alternative connection details for the haunch system: hinged (left side, implemented in specimens THR1 \& THR2) or welded (right side, implemented in specimen THR3). 
Table IV. Properties of haunch elements.

\begin{tabular}{lccccccc}
\hline Specimen & $\begin{array}{c}\text { Steel } \\
\text { grade }\end{array}$ & $\begin{array}{c}E \text {-modulus } \\
(\mathrm{MPa})\end{array}$ & $\begin{array}{c}f_{y} \\
(\mathrm{MPa})\end{array}$ & $\begin{array}{c}\text { Fuse diameter } \\
(\mathrm{mm})\end{array}$ & $\begin{array}{c}F_{y} \\
(\mathrm{kN})\end{array}$ & $\begin{array}{c}\text { Equivalent axial } \\
\text { stiffness } K_{d}(\mathrm{kN} / \mathrm{m})\end{array}$ & $\begin{array}{c}\text { Connection } \\
\text { type }\end{array}$ \\
\hline THR1 & 430 & 176 & 498 & 14 & 76 & 107000 & Hinged \\
THR2 & 300 & 195 & 340 & 9 & 22 & 109000 & Hinged \\
THR3 & 300 & 235 & 325 & 19 & 90 & 110000 & Welded \\
\hline
\end{tabular}

Table V. Expected hierarchy of strength and actual 'margin' or safety factors $\Phi_{i}$ between sequence of events (design parameters: $L^{\prime}=400 \mathrm{~mm}, \alpha=45, K_{d}=100000 \mathrm{kN} / \mathrm{m}, \Phi_{1}$ and $\Phi_{2}=0.85$ ).

\begin{tabular}{|c|c|c|c|c|c|c|c|c|}
\hline $\begin{array}{l}\text { Limit on } \\
\frac{p_{\mathrm{t}}}{\sqrt{f_{c}^{\prime}}}\end{array}$ & $\begin{array}{c}K_{d} \\
(\mathrm{kN} / \mathrm{m})\end{array}$ & $\beta$ & $\begin{array}{c}\bar{V}_{\mathrm{c}, \text { beam-hinge }} \\
(\mathrm{kN})\end{array}$ & $\begin{array}{c}\bar{V}_{\mathrm{c}, \text { col-hinge }} \\
(\mathrm{kN})\end{array}$ & $\begin{array}{c}\bar{V}_{\mathrm{c}, \text { joint }} \\
(\mathrm{kN})\end{array}$ & $\begin{array}{c}\frac{\bar{V}_{\mathrm{c}, \text { beam-hinge }}}{\bar{V}_{\mathrm{c}, \text { col-hinge }}} \\
\quad\left(\leqslant \Phi_{1}\right)\end{array}$ & $\begin{array}{c}\frac{\bar{V}_{\mathrm{c}, \text { col-hinge }}}{\bar{V}_{\mathrm{c}, \text { joint }}} \\
\left(\leqslant \Phi_{2}\right)\end{array}$ & $\begin{array}{c}\frac{\bar{V}_{\mathrm{c}, \text { beam-hinge }}}{\bar{V}_{\mathrm{c}, \text { joint }}} \\
\left(\leqslant \Phi_{1} \Phi_{2}\right)\end{array}$ \\
\hline 0.19 & 100000 & 2.1 & 25 & 35 & 41.5 & 0.71 & 0.84 & 0.6 \\
\hline 0.29 & 100000 & 2.1 & 25 & 35 & 50.7 & 0.71 & 0.69 & 0.49 \\
\hline
\end{tabular}

1 refers to the haunch axial element itself without including the effects of the hinged or welded base connections. These effects were included in the design process by using appropriate safety

3 factors $\Phi_{i}$.

The yielding haunch was designed for a yield force $F_{y}=20 \mathrm{kN}$. This value of $F_{y}$ was chosen to

5 be slightly lower than the expected maximum axial force in the elastic haunch system. This force was also measured experimentally in the experiment THR 1 as $F_{\max }=25 \mathrm{kN}$. As discussed by

7 Christopoulos and Filiatrault [19], in the case of a yielding haunch, the system behaves similarly to systems with non-yielding haunches (described in the previous paragraphs) until the forces in

9 the passive haunches reach the strength of the device $F_{y}$. Up to that point, the moment and shear in the beam follow the diagram shown in the top row of Figure 4 and are dependent on the elastic

11 properties and geometry of the haunches. When the haunches reach their yield load, assuming they do not exhibit significant post-yielding stiffness, any additional lateral loads applied to the system

13 will cause internal forces following the distribution presented in Figure 4 (without haunch). After the device reaches its yield load $F_{y}$, the moment in the beam at the face of the column will increase

15 at a much higher rate than it does before the haunch yields. If the beam does not form a plastic hinge at the location where the haunches are attached after the devices have slipped or yielded,

17 the joint will suffer damage. Considering this, $F_{y}$ must be chosen such that when the devices yield, the moment at the location where the haunches are attached to the beam is sufficiently close

19 to the plastic moment of the beam to assure that the damage to the joint does not occur before yielding of the beam. In general terms, for the elasto-plastic haunches, the design is first carried

21 out assuming elastic elements following the procedure described above and then the lowest value of $F_{y}$ that assures yielding of the beam before the joint is damaged is determined.

\section{5.5. Experimental results of the retrofitted solutions}

5.5.1. Response of THR1 (elastic haunch with hinge connection). Figure 10 shows the behaviour 25 of the specimen retrofitted with the elastic haunch system (THR1). As targeted in the design 


\section{EQE 600}
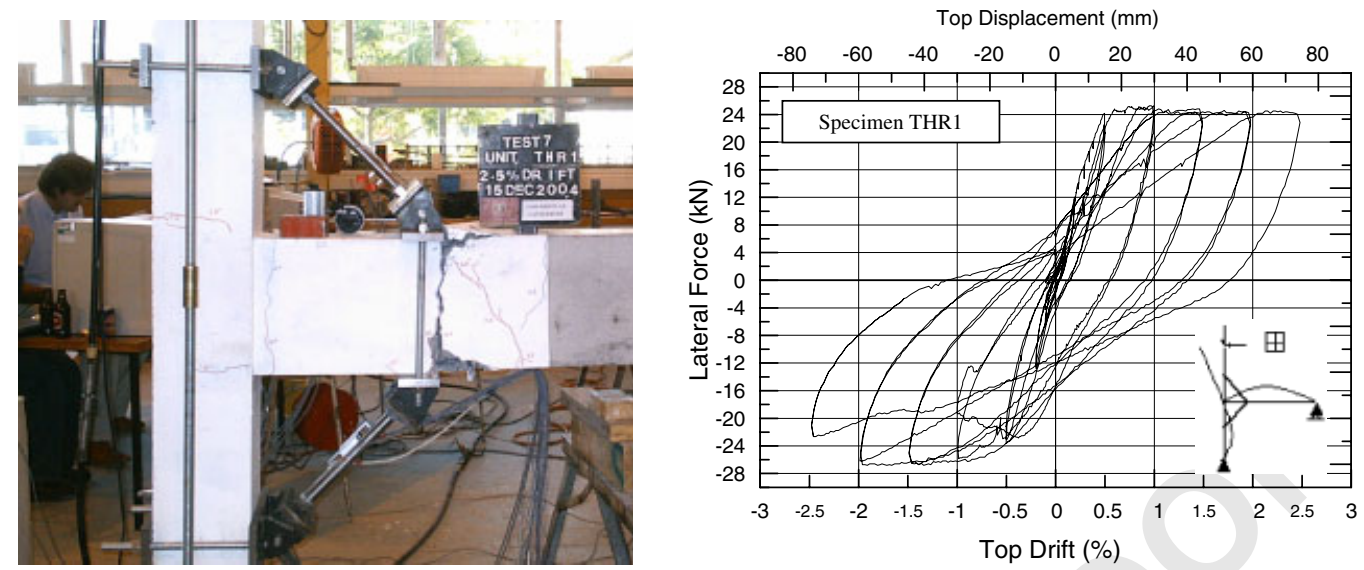

Figure 10. Experimental behaviour of specimen THR1 (elastic hinged haunch): relocation of plastic hinge and hysteresis loop.

1 process, no shear damage occurred in the joint panel zone region, while a more desirable flexural hinging behaviour within a weak-beam strong column mechanism was observed. The flexural hinge was established by the formation and progressive widening of a main flexural crack at the haunch-to-beam connection (this localized hinging mechanism is typical of beam section with plain reinforcement). As a result, a more stable hysteretic response with increased energy dissipation was observed when compared to the as-built specimen response (see Figure 8). Moreover, due to

7 the relocation of the plastic hinge away from the column interface, the longitudinal beam bars can rely on a full anchorage/development length as shown by the limited pinching effect in the

\section{9 hysteresis.}

When comparing the improved global hysteretic behaviour of the retrofitted configuration to

11 the as-built solution (see Figure 8), it is also worth noting that, as a result of the inversion of the hierarchy of strength, a substantial increase in the global subassembly lateral strength is observed.

13 This increase of strength is not due to the increase of strength of any individual member of the system but rather to the inversion of the hierarchy of strength of the same members. More

15 specifically, the lateral load capacity of the as-built specimen, corresponding to the occurrence of

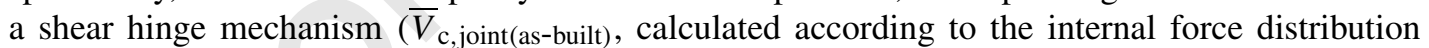

17 for the as-built configuration) has increased, thanks to the retrofit solution, to the value of lateral load capacity corresponding to the formation of a plastic hinge in the beam $\left(V_{\mathrm{c}, \text { beam-hinge }}\right.$ as per

19 Equation (10)).

5.5.2. Response of THR2 (yielding haunch with hinge connection). The experimental response of

21 the THR2 specimen, which incorporated a yielding haunch solution with a hinge connection, also achieved the targeted protection of the panel zone as well as the reversal of the strength hierarchy

23 to force a flexural hinge in the beam. As in the previous test (THR1), a stable hysteretic response with good energy dissipation was observed with marked pinching occurring only at higher drift

25 levels (beyond 2\%) due to the wide opening/closing of the main flexural crack a the beam/haunch connection interface which caused some shear sliding. Based on the global hysteretic response and

27 the strain gauge readings on the yielding haunch element, the dissipating solution did not seem 

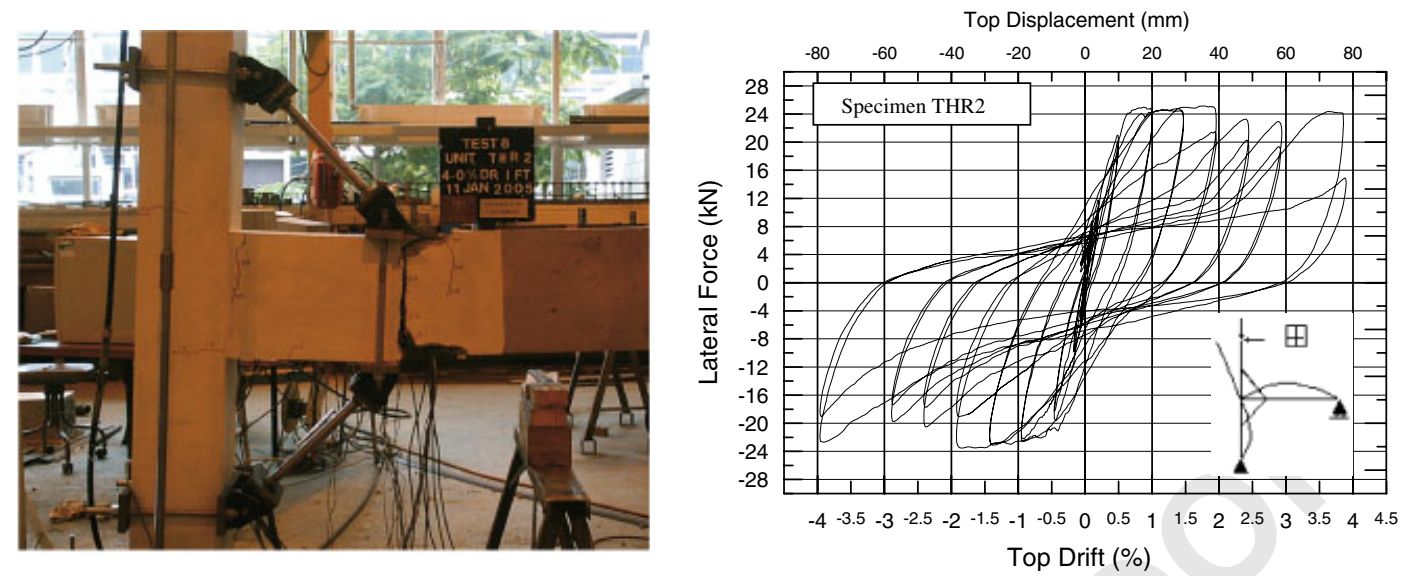

Figure 11. Experimental behaviour of specimen THR2 (yielding hinged haunch): relocation of plastic hinge and hysteresis loop.

1 to be particularly effective in improving the energy dissipation of the system, when compared to the elastic solution adopted in the THR1 specimen. Due to the characteristics of these pre-

3 1970s RC frame systems, a complex trade-off between a high haunch stiffness to activate the haunch before excessive rotation demand occurs in the joint and the need to provide a sufficient

5 displacement excursion of the haunch device to guarantee additional hysteretic energy dissipation (while still protecting the joint region from excessive damage) is difficult to achieve. For the system

7 in this experimental study, the use of a dissipating haunch was therefore not a viable solution (Figure 11).

9 5.5.3. Haunch stiffness in THR1 and THR2 specimens. The first version of the haunch system, implemented in the specimens THR1 and THR2, was based on the use of a hinged connection

11 (see Figure 9, left). Due to the flexibility of the hinged base supports and to the tolerances within the mechanical connections, the actual global stiffness of the haunch device (i.e. haunch

13 plus base hinges and plate), measured experimentally, was significantly lower than the 'factored' design value ( $K_{d}$ experimental $\cong 22000-25000 \mathrm{kN} / \mathrm{m}$ instead of the targeted $K_{d}=100000 \mathrm{kN} / \mathrm{m}$ ).

15 However, thanks to the conservatism built into the design approach through higher safety factors accounting for different uncertainties expected at a first stage, both the THR 1 and THR2 solutions

17 achieved the major goal of inverting the hierarchy of strength while protecting the panel zone region.

19 5.5.4. Response of THR3 (elastic haunch with welded connection). In the second phase of the experimental program, focus was set on improving the constructability and effectiveness of the

21 haunch. This led to the development of a second generation solution for the haunch elements. By welding the haunch axial element directly to the plate connection (see Figure 9, right), stiffness

23 losses in the haunch connections were eliminated. The equivalent stiffness of the slightly longer haunch element was kept equal to the targeted $K_{d}=100000 \mathrm{kN} / \mathrm{m}$ to allow for comparisons with 25 specimens THR1 and THR2. 


\section{EQE 600}
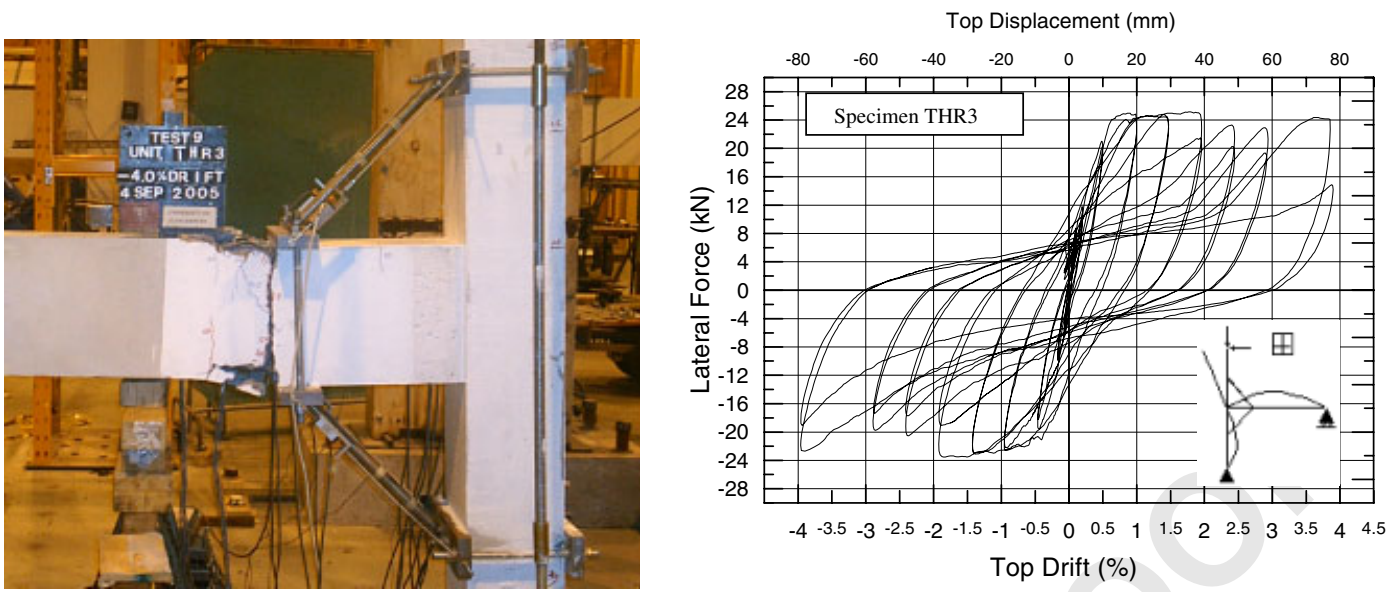

Figure 12. Experimental behaviour of specimen THR3 (elastic welded haunch): relocation of plastic hinge and hysteresis loop.

1 As shown in Figure 12, the THR3 retrofit intervention with the improved haunch detail was successful in forcing a plastic hinge to form in the beam and in protecting the panel zone region.

3 However, unlike tests THR1 and THR2, the global haunch stiffness measured experimentally was almost the same as the targeted design value of $K_{d}=100000 \mathrm{kN} / \mathrm{m}$. This second generation

5 haunch solution allows for a very reliable control of the haunch stiffness, and therefore the calculations of internal forces used for the design of the retrofit solution can be done more

7 adequately. Reducing the conservatism that was built in to the design of THR1 and THR2 specimens (by increasing the safety factors) increases the number of feasible haunch configurations that can

9 be considered.

5.5.5. Redistribution of deformation demand and fuse effect of the beam hinge. A further confir-

11 mation of the efficiency of the proposed retrofit solution in protecting the panel zone region from excessive damage while developing a plastic hinge in the beam, is given in Figure 13, where the

13 experimental relative contributions to the total drift from beam-column and panel zone region are shown, for the as-built and the retrofitted specimens.

15 While in the as-built solution (TDP2 specimen) the occurrence of a shear hinge mechanism leads to a concentration of the subassembly rotation demand in the panel zone, while column and beam

17 deformation/rotation demand remain limited, the opposite behaviour is observed in the retrofitted configurations. The development of a flexural mechanism (plastic hinge) in the beam acts as a

19 protective fuse for the panel zone. A quantitative summary of the experimental results in terms of subassembly overall strength, initial stiffness and energy dissipation capacity of the as-built

21 and retrofitted configurations is given in Table VI as further confirmation of the efficiency of the proposed retrofit solution. It can be noted that the haunch solution leads to an appreciable increase

23 in the lateral strength of the subassembly from values in the order of $14-16 \mathrm{kN}$, corresponding to shear damage and failure of the joint panel zone region, to values of $23-26 \mathrm{kN}$ (increase of 55 and

25 83\%), corresponding to the development of a plastic hinge in the beam in line with the desired and more favourable weak-beam strong column inelastic mechanism of the overall frame system. 

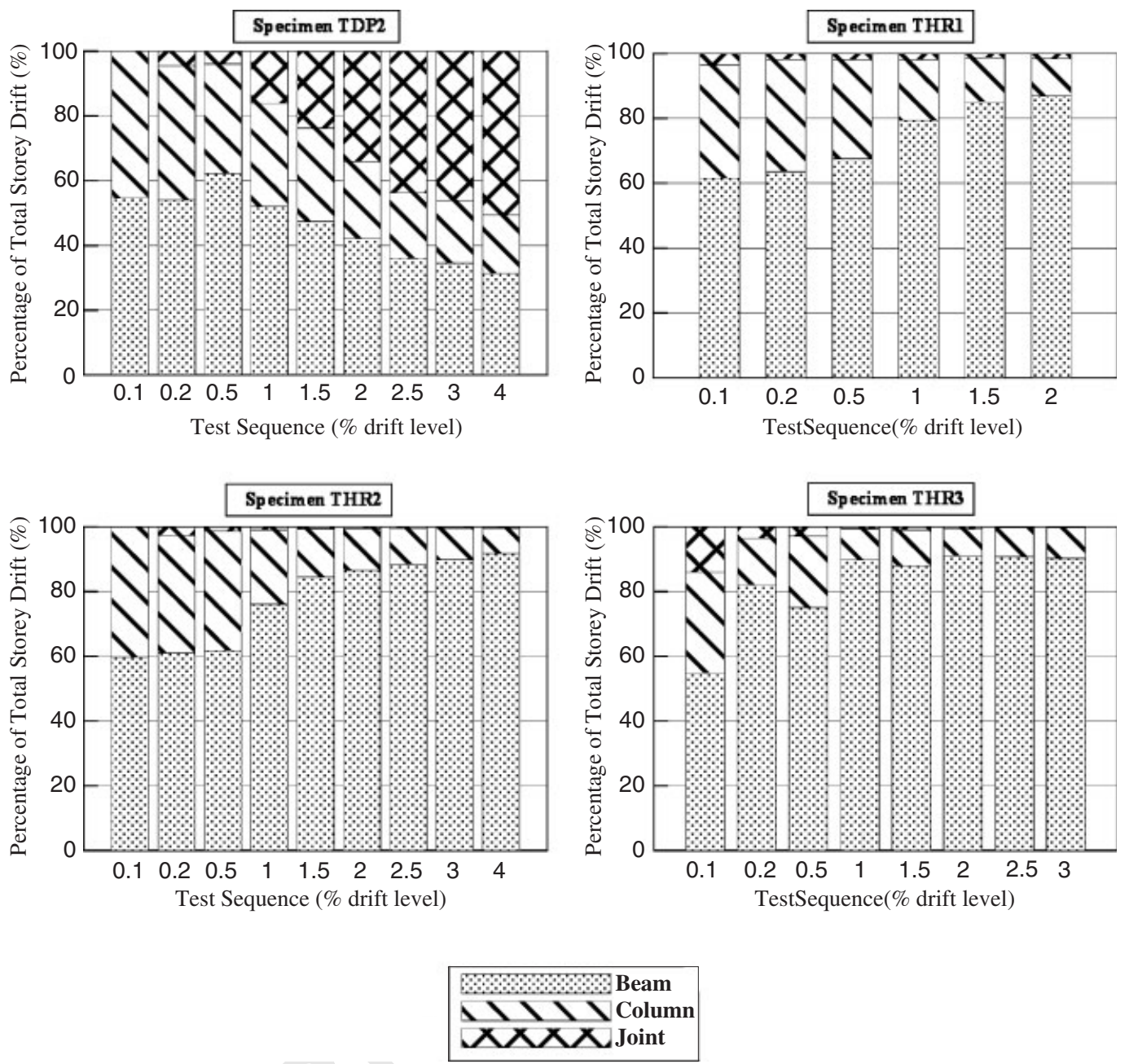

Figure 13. Contributions to subassembly drift of beam, column and joint in as-built and retrofitted solutions (positive loading direction).

1 The more stable flexural mechanism in the beam also allows for a substantial improvement in the energy dissipation capacity of the system, thus further reduction of the displacement demand, with equivalent viscous damping values, $\xi$, moving from $13-15 \%$ (at 1 and $2 \%$ of drift) to $21-25 \%$ (increase of $45-93 \%$ ). The consistently observed increase in the 'initial' stiffness of the subassembly (evaluated as elastic stiffness of an equivalent bilinear force-displacement envelope) from approximately $1.5-1.6$ to $2.7-3.1 \mathrm{kN} / \mathrm{m}(+70-100 \%)$, could also provide beneficial effects

7 in limiting excessive deformations even under moderate earthquake ground motions. Preliminary numerical results on frame systems retrofitted with haunch solutions [24] have also shown that

9 there is only a marginal increase in the floor accelerations as a result of the installation of stiffening haunches. 


\section{EQE 600}

Table VI. Summary of experimental response of as-built and retrofitted configurations.

\begin{tabular}{|c|c|c|c|c|c|c|c|c|}
\hline \multirow[b]{2}{*}{ Specimen } & \multicolumn{2}{|c|}{$\begin{array}{l}\text { Initial stiffness } \\
(\mathrm{kN} / \mathrm{mm})\end{array}$} & \multicolumn{2}{|c|}{$\begin{array}{c}\text { Ultimate } \\
\text { strength }(\mathrm{kN})\end{array}$} & \multicolumn{4}{|c|}{$\begin{array}{l}\text { Equivalent viscous } \\
\text { damping }(\%)\end{array}$} \\
\hline & $\begin{array}{l}\text { Positive } \\
\text { loading }\end{array}$ & $\begin{array}{c}\text { Negative } \\
\text { loading }\end{array}$ & $\begin{array}{l}\text { Positive } \\
\text { loading }\end{array}$ & $\begin{array}{c}\text { Negative } \\
\text { loading }\end{array}$ & $\begin{array}{c}0.5 \% \\
\text { drift }\end{array}$ & $\begin{array}{c}1 \% \\
\text { drift }\end{array}$ & $\begin{array}{l}2 \% \\
\text { drift }\end{array}$ & $\begin{array}{l}3 \% \\
\text { drift }\end{array}$ \\
\hline TDP2 (as-built) & 1.60 & 1.56 & 15.95 & 14.3 & 15.0 & 14.5 & 13.5 & 15.0 \\
\hline THR1 & 3.06 & 3.00 & 24.5 & 26.1 & 10.9 & 23.5 & 26.2 & - \\
\hline THR2 & 2.70 & 2.75 & 25.2 & 23.2 & 11.7 & 21.2 & 25.6 & 18.7 \\
\hline THR3 & 3.12 & 3.10 & 25.0 & 25.2 & 13.3 & 21.0 & 26.3 & 20.3 \\
\hline
\end{tabular}

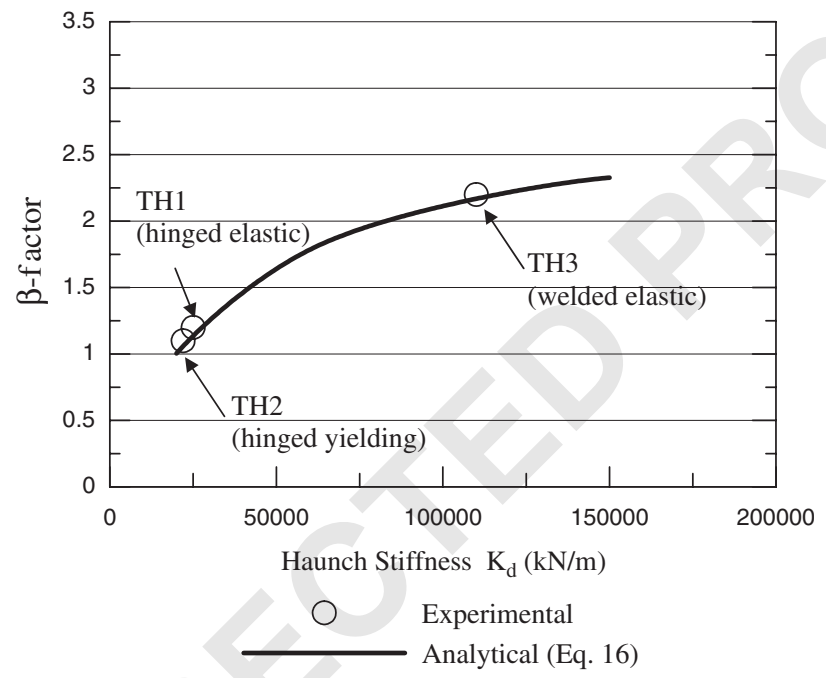

Figure 14. Analytical-experimental comparison of $\beta$-factor (haunch contribution).

\section{5.6. Validation of the design procedure with experimental results}

The efficiency of the overall retrofit strategy in terms of controlling the hierarchy of strength and

3 sequence of mechanisms can be further appreciated by comparing the experimental results with the expected distribution of internal forces in the beam and column, the joint shear demand (in terms

5 of either nominal shear force $V_{j h}$, principle tensile stress $p_{\mathrm{t}}$, or equivalent moment $M_{j}=M_{\mathrm{bc}}$ ) as well as with predicted lateral load capacities corresponding to the occurrence of each mechanism.

7 To assess the validity of the proposed analytical approach, actual material properties, along with the actual values of the haunch global stiffness (as measured experimentally) were used to back-

9 calculate the responses of the retrofited specimens which were then compared to the experimentally measured responses. The formulation given in Equation (16) for the calculation of the $\beta$-factor

11 was used to account for column flexibility. Figure 14 shows the comparison between the $\beta$-factors derived from experimental measurements with the values calculated using Equation (16) with the

13 properties of the tested haunches. 


\section{EQE 600}

1 A more complete comparison between analytically derived and experimental results is presented in Table VII, in terms of (i) the $\beta$-factor, (ii) the level of principle tensile stresses, $p_{\mathrm{t}}$, developed

3 in the joint (normalized by $\sqrt{f_{\mathrm{c}}^{\prime}}$ ), (iii) the beam moments at the joint interface, $M_{\mathrm{bc}}$, (iv) the beam moments at the haunch connection, $M_{\mathrm{b}(\max )}$, and (v) the subassembly lateral force capacity

5 corresponding to the development of the desired plastic hinge event, $\bar{V}_{\text {c,beam-hinge. As can be seen }}$ in this table, the proposed analytical procedure captures well all the measured responses. Provided

7 that appropriate mechanical connection details are adopted for the haunch device to limit the observed reduction of stiffness as well as the slackness of the connection (i.e. welded solution

9 versus hinged), the effects of the overall retrofit solution can be controlled in the design with good confidence.

11 To study the effect of variable transverse reinforcement spacing, to represent lower and upper bounds in older construction practices a comparison between shear demand and capacity of columns

13 and beam elements in the (scaled specimen) retrofitted specimens was carried out according to the NZS3101:2005 guidelines [21] assuming an increase of 50 and 100\% in the transverse

15 reinforcement spacing and is presented in Table VIII. It can be noted that with the $100 \%$ increase in spacing, shear capacities are still sufficient to resist the increased levels of shear forces. However,

17 as indicated in the step-by-step design procedure presented in the previous paragraphs, a detailed analysis must carried to assure that the desired hierarchy of strength is satisfied, with acceptable margins of safety for undesirable mechanisms such as shear failures.

Table VII. Analytical-experimental comparison of the efficiency of the haunch retrofit solution.

\begin{tabular}{lcclcccc}
\hline Specimen & $\begin{array}{c}K_{d} \\
(\mathrm{kN} / \mathrm{m})\end{array}$ & & $\beta$ & $\frac{p_{\mathrm{t}}}{\sqrt{f_{c}^{\prime}}}$ & $\begin{array}{c}M_{\mathrm{bc}} \\
(\mathrm{kNm})\end{array}$ & $\begin{array}{c}M_{\mathrm{b}(\max )} \\
(\mathrm{kNm})\end{array}$ & $\begin{array}{c}\bar{V}_{\mathrm{c}, \text { beam-hinge }} \\
(\mathrm{kN})\end{array}$ \\
\hline THR1 & 25000 & Analytical & 1.15 & 0.22 & 22.4 & 30 & 22.8 \\
& & Experimental & 1.2 & 0.21 & 24.3 & 31.7 & 23.7 \\
THR2 & 22000 & Analytical & 1.07 & 0.24 & 23.9 & 30 & 22.8 \\
& & Experimental & 1.1 & 0.19 & 20.8 & 29 & 22.14 \\
THR3 & \multirow{2}{*}{110000} & Analytical & 2.17 & 0.06 & 4.9 & 30 & 22.8 \\
& & Experimental & 2 & 0.10 & 10.3 & 31.1 & 24.3 \\
\hline
\end{tabular}

Table VIII. Verification of shear capacity versus demand of columns and beam elements in the retrofitted configuration assuming variable transverse reinforcement (spacing).

\begin{tabular}{|c|c|c|c|c|c|c|c|}
\hline \multirow[b]{2}{*}{ Specimens } & 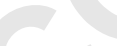 & \multirow[b]{2}{*}{$\begin{array}{c}\text { Shear } \\
\text { demand }(\mathrm{kN})\end{array}$} & \multirow[b]{2}{*}{$\begin{array}{l}\text { Transverse reinforcement } \\
\text { spacing } s(\mathrm{~mm})\end{array}$} & \multicolumn{4}{|c|}{ Shear capacity $(\mathrm{kN})$} \\
\hline & & & & $V_{S}$ & $V_{\mathrm{c}}$ & $\begin{array}{l}\text { Total } \\
\text { (PPHZ) }\end{array}$ & $\begin{array}{c}\text { Total } \\
\text { (outside PPHZ) }\end{array}$ \\
\hline \multirow{6}{*}{$\begin{array}{l}\text { THR1,THR2, } \\
\text { THR3 }\end{array}$} & & & $s=100$ & 46 & & 46 & 76 \\
\hline & Column & 24 & $s=150$ & 31 & 30 & 31 & 61 \\
\hline & & & $s=200$ & 23 & & 23 & 53 \\
\hline & & & $s=133$ & 53 & & 53 & 90 \\
\hline & Beam & 32 & $s=200$ & 35 & 37 & 35 & 72 \\
\hline & & & $s=266$ & 26 & & 26 & 63 \\
\hline
\end{tabular}

Note: Evaluation of shear capacity according to NZS3101 [21]. PPHZ refers to a potential plastic hinge zone where the shear contribution from concrete, $V_{\mathrm{c}}$, is neglected. 


\section{EQE 600}

\section{CONCLUSIONS}

A simple and effective retrofit strategy for retrofitting existing reinforced concrete buildings designed mostly for gravity loads prior to the introduction of modern seismic code provisions has been presented. A simplified design approach based on an analytical formulation for the forces

5 in the beam-column system retrofitted with the proposed haunch system has been suggested. The goal of the proposed solution is to reverse the hierarchy of strength by forcing a plastic hinge

7 in the beam while protecting the panel zone from excessive cracking and strength degradation. An experimental program was carried out to verify the effectiveness of the proposed technique

9 to significantly enhance the response of the beam-column subassemblies, but also to validate the proposed analytical formulation and design procedure.

11 Results from a control benchmark test were first presented where the deficiencies related with the joint panel zone shear damage were confirmed. The design and practical implementation of

13 a simple haunch element consisting of a threaded steel bar fastened to hinged plates that are connected to the beams and columns was then carried out. The retrofitted specimens displayed a

15 substantially enhanced response when compared to the non-retrofitted specimens: damage to the joint was eliminated and a flexural plastic hinge formed in the beam at the location of the beam-

17 haunch connection. This resulted in an increase in the system lateral strength, a stable hysteretic behaviour and enhanced energy dissipation capacity. The second of these specimens was designed

19 to yield at a force slightly lower than the maximum force developed in the first specimen to enhance the energy dissipation capacity of the system. For this tested configuration, the yielding of

21 the haunch element did not significantly enhance the performance of the proposed retrofit strategy although it did meet the design requirement of protecting the panel zone while forming a flexural

23 hinge in the beam. To further improve the performance of the haunch, a second generation detail which used a welded haunch was then built and validated through a third experiment. The third

25 experiment also achieved the desired response of beam flexural hinging and protection of the panel zone. The stiffness of the haunch element measured in this third experiment was very close to

27 the expected value. Results obtained using the proposed analytical derivations were very close to results measured experimentally thus validating the steps that are suggested for the design of the proposed retrofit solution.

Further studies on the application of this retrofit technique to other types of non-seismically

31 designed RC frames (i.e. shallow and wide beam, flat slabs) and on the practical definition of alternative elastic or dissipating haunch elements are needed. Experimental investigations on the

33 local behaviour of the haunch system including appropriate fastening solutions to the existing frame are currently underway. Finally, investigations on the multiple aspects of the global response (3-D

35 bi-axial, larger assemblies with floor systems) of systems retrofitted with the proposed technique are also being carried out.

\section{ACKNOWLEDGEMENTS}

The financial support of the NZ Foundation of Science and Technology through the FRST-Research Program 'Retrofit Solutions for NZ' is acknowledged. The financial support of the National Science and Engineering Research Council of Canada is also greatly appreciated.

\section{REFERENCES}

39 1. Aycardi LE, Mander JB, Reinhorn AM. Seismic resistance of reinforced concrete frame structures designed only for gravity loads: experimental performance of subassemblages. ACI Structural Journal 1994; 91(5):552-563. 
2. Beres A, Pessiki S, White R, Gergely P. Implications of experimental on the seismic behaviour of gravity load designed RC beam-column connections. Earthquake Spectra 1996; 12(2):185-198.

3. Hakuto S, Park R, Tanaka H. Seismic load tests on interior and exterior beam-column joints with substandard reinforcing details. ACI Structural Journal 2000; 97(1):11-25.

4. Bing Li, Yiming W, Tso-Chien P. Seismic behaviour of non-seismically detailed interior beam-wide column joints-Part I: Experimental results and observed behaviour. ACI Structural Journal 2002; 99(6):791-802.

5. Park R. A summary of results of simulated seismic load tests on reinforced concrete beam-column joints, beams and columns with substandard reinforcing details. Journal of Earthquake Engineering 2002; 6(2):1-27.

6. Pampanin S, Calvi GM, Moratti M. Seismic behaviour of RC beam-column joints designed for gravity loads. Twelfth European Conference on Earthquake Engineering, London, Paper No. 726, 2002.

7. Calvi GM, Magenes G, Pampanin S. Experimental test on a three storey RC frame designed for gravity only. Twelfth European Conference on Earthquake Engineering, London, Paper No. 727, 2002.

13 8. Sugano S. State of the art in techniques for rehabilitation of buildings. Proceedings of the 11th World Conference on Earthquake Engineering, Acapulco, Mexico, Paper No. 2175, 1996.

15 9. Federation International du Béton. Externally bonded FRP reinforcement for RC structures. FIB Bulletin 14, Lausanne, 2001.

17 10. Dolce M, Cardone D, Marnetto R. Implementation and testing of passive control devices based on shape memory alloys. Earthquake Engineering and Structural Dynamics 2000; 29(7):945-968.

19 11. Calvi GM, Magenes G, Pampanin S. Relevance of beam-column damage and collapse in RC frame assessment. Journal of Earthquake Engineering 2002; sup6(2) (Special issue).

21 12. Pampanin S, Bolognini D, Pavese A. Performance-based seismic retrofit strategy for existing reinforced concrete frame systems using FRP composites. ASCE Journal of Composites for Construction, accepted for publication.

23 13. Pampanin S, Magenes G, Carr A. Modelling of shear hinge mechanism in poorly detailed RC beam-column joints. Proceedings of the FIB Symposium Concrete Structures in Seismic Regions, Athens, Paper No. 171, 2003.

14. Hertanto E. Seismic assessment of pre-1970 reinforced concrete frame buildings. M.S. Thesis, Department of Civil Engineering, University of Canterbury, Christchurch, New Zealand, 2006.

27 15. Cosenza G, Manfredi G, Verderame G. Seismic assessment of gravity load designed RC frames: critical issues in structural modelling. Journal of Earthquake Engineering 2002; 6(1):101-122 (Special issue).

29 16. Lowes LN, Altoontash A. Modeling reinforced-concrete beam-column joints subjected to cyclic loading. Journal of Structural Engineering (ASCE) 2003; 129(12):1686-1697.

31 17. Yu Q-S, Noel S, Uang C-M. Experimental studies on seismic rehabilitation of pre-Northridge steel moment connections: RBS and haunch approach. Report No. SSRP-97/09, University of California at San Diego, La Jolla, CA, 1997.

18. Gross JL, Engelhardt MD, Uang C-M, Kasai K, Iwankin NR. Modification of Existing Welded Steel Moment Frame Connections for Seismic Resistance. American Institute of Steel Construction, 1999.

19. Christopoulos C, Filiatrault A. Non-invasive passive energy dissipating devices for the retrofit of steel structures. Proceedings of the International Conference on the Behaviour of Steel Structures in Seismic Areas-STESSA 2000, Montreal, Canada, 2000; 387-394.

39 20. Priestley MJN. Displacement-based seismic assessment of reinforced concrete buildings. Journal of Earthquake Engineering 1997; 1(1):157-192.

41 21. NZS 3101. The Design of Concrete Structures. Standards New Zealand: Wellington, NZ, 2005.

22. Fabbrocino G, Verderame G, Manfredi G. Experimental behaviour of anchored smooth rebars in old type reinforced concrete buildings. Engineering Structures 2005; 27(10):1575-1585.

23. Chen TH. Development of a low-invasive seismic retrofit solution for under-designed frame systems based on a metallic haunch. M.S. Thesis, Department of Civil Engineering, University of Canterbury, Christchurch, New Zealand, 2006.

47 24. Pampanin S, Christopoulos C. Non-invasive retrofit of existing RC frames designed for gravity loads only. FIB Symposium on Concrete Structure in Seismic Regions, Athens, 2003. 
F John Wiley \& Sons Ltd

The Atrium, Southern Gate, Chichester West, Sussex PO19 8s

WILEY

\section{Author Queries For $\quad$ EQE $\quad 600$}

While preparing this paper/manuscript for typesetting, the following queries have arisen

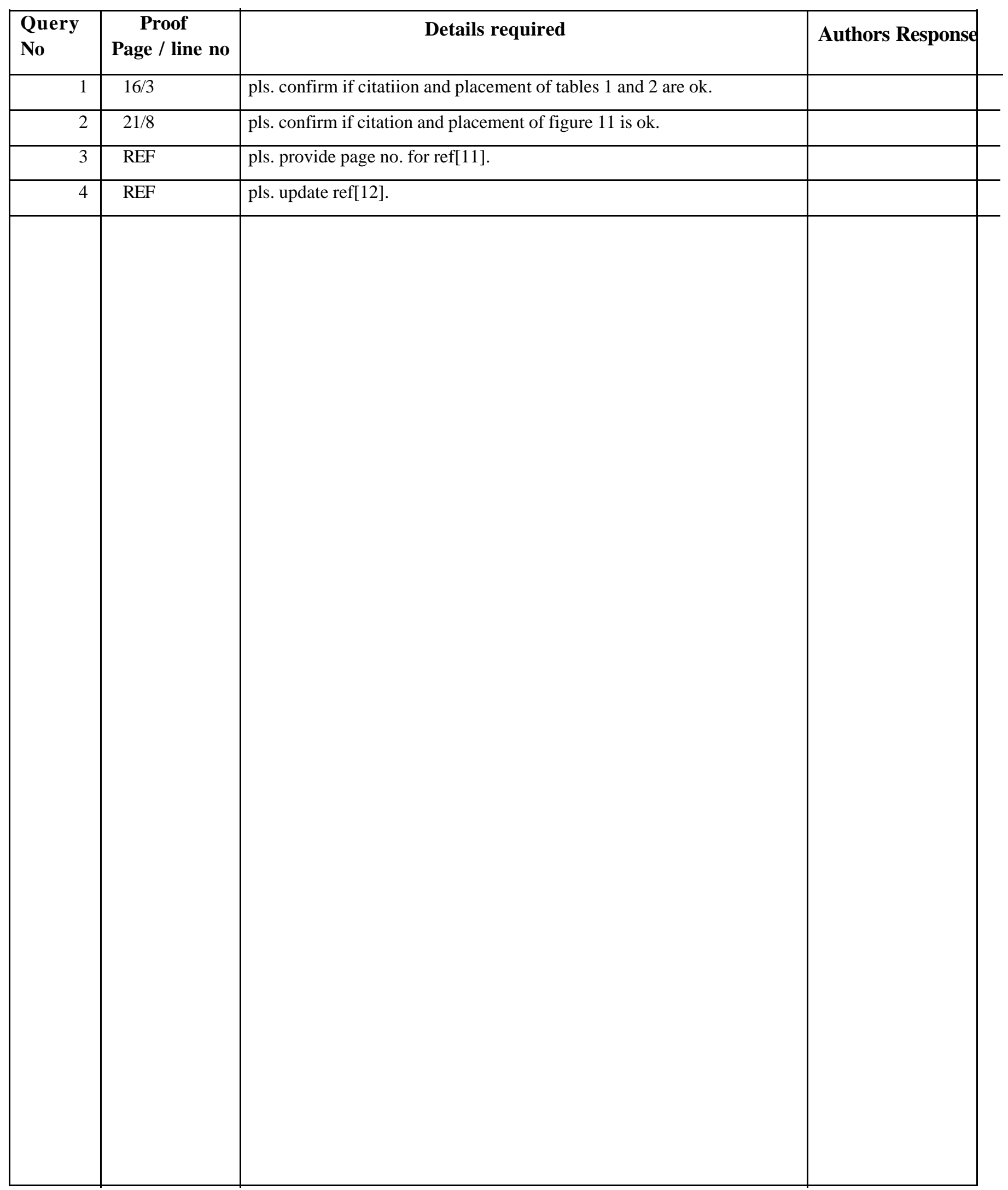


(the "Contribution") written by

(the "Contributor") for publication in..

(the "Journal) published by John Wiley \& Sons Ltd ("Wiley").

In order to expedite the publishing process and enable Wiley to disseminate your work to the fullest extent, we need to have this Copyright Transfer Agreement signed and returned to us with the submission of your manuscript. If the Contribution is not accepted for publication this Agreement shall be null and void.

\section{A. COPYRIGHT}

1. The Contributor assigns to Wiley, during the full term of copyright and any extensions or renewals of that term, all copyright in and to the Contribution, including but not limited to the right to publish, republish, transmit, sell, distribute and otherwise use the Contribution and the material contained therein in electronic and print editions of the Journal and in derivative works throughout the world, in all languages and in all media of expression now known or later developed, and to license or permit others to do so.

2. Reproduction, posting, transmission or other distribution or use of the Contribution or any material contained therein, in any medium as permitted hereunder, requires a citation to the Journal and an appropriate credit to Wiley as Publisher, suitable in form and content as follows: (Title of Article, Author, Journal Title and Volume/Issue Copyright $\odot$ [year] John Wiley \& Sons Ltd or copyright owner as specified in the Journal.)

\section{B. RETAINED RIGHTS}

Notwithstanding the above, the Contributor or, if applicable, the Contributor's Employer, retains all proprietary rights other than copyright, such as patent rights, in any process, procedure or article of manufacture described in the Contribution, and the right to make oral presentations of material from the Contribution.

\section{OTHER Rights OF CONTRIBUtOR}

Wiley grants back to the Contributor the following:

1. The right to share with colleagues print or electronic "preprints" of the unpublished Contribution, in form and content as accepted by Wiley for publication in the Journal. Such preprints may be posted as electronic files on the Contributor's own website for personal or professional use, or on the Contributor's internal university or corporate networks/intranet, or secure external website at the Contributor's institution, but not for commercial sale or for any systematic external distribution by a third party (eg: a listserver or database connected to a public access server). Prior to publication, the Contributor must include the following notice on the preprint: "This is a preprint of an article accepted for publication in [Journal title] Copyright $\odot$ (year) (copyright owner as specified in the Journal)". After publication of the Contribution by Wiley, the preprint notice should be amended to read as follows: "This is a preprint of an article published in [include the complete citation information for the final version of the Contribution as published in the print edition of the Journal]" and should provide an electronic link to the Journal's WWW site, located at the following Wiley URL: http://www.interscience.wiley.com/. The Contributor agrees not to update the preprint or replace it with the published version of the Contribution.

2. The right, without charge, to photocopy or to transmit on-line or to download, print out and distribute to a colleague a copy of the published Contribution in whole or in part, for the Contributor's personal or professional use, for the advancement of scholarly or scientific research or study, or for corporate informational purposes in accordance with paragraph D2 below.

3. The right to republish, without charge, in print format, all or part of the material from the published Contribution in a book written or edited by the Contributor

4. The right to use selected figures and tables, and selected text (up to 250 words) from the Contribution, for the Contributor's own teaching purposes, or for incorporation within another work by the Contributor that is made part of an edited work published (in print or electronic format) by a third party, or for presentation in electronic format on an internal computer network or external website of the Contributor or the Contributor's employer. The abstract shall not be included as part of such selected text.

5. The right to include the Contribution in a compilation for classroom use (course packs) to be distributed to students at the Contributor's institution free of charge or to be stored in electronic format in datarooms for access by students at the Contributor's institution as part of their course work (sometimes called "electronic reserve rooms") and for in-house training programmes at the Contributor's employer.

\section{CONTRIBUTIONS OWNED BY EMPLOYER}

1. If the Contribution was written by the Contributor in the course of the Contributor's employment (as a "work-made-for-hire" in the course of employment), the Contribution is owned by the company/employer which must sign this Agreement (in addition to the Contributor's signature), in the space provided below. In such case, the company/employer hereby assigns to Wiley, during the full term of copyright, all copyright in and to the Contribution for the full term of copyright throughout the world as specified in paragraph A above.

2. In addition to the rights specified as retained in paragraph B above and the rights granted back to the Contributor pursuant to paragraph $\mathrm{C}$ above, Wiley hereby grants back, without charge, to such company/employer, its subsidiaries and divisions, the right to make copies of and distribute the published Contribution internally in print format or electronically on the Company's internal network. Upon payment of the Publisher's reprint fee, the institution may distribute (but not re-sell) print copies of the published Contribution externally. Although copies so made shall not be available for individual re-sale, they may be included by the company/employer as part of an information package included with software or other products offered for sale or license. Posting of the published Contribution by the institution on a public access website may only be done with Wiley's written permission, and payment of any applicable fee(s). 


\section{E. GOVERNMENT CONTRACTS}

In the case of a Contribution prepared under US Government contract or grant, the US Government may reproduce, without charge, all or portions of the Contribution and may authorise others to do so, for official US Government purposes only, if the US Government contract or grant so requires. (Government Employees: see note at end.)

\section{F. COPYRIGHT Notice}

The Contributor and the company/employer agree that any and all copies of the Contribution or any part thereof distributed or posted by them in print or electronic format as permitted herein will include the notice of copyright as stipulated in the Journal and a full citation to the Journal as published by Wiley.

\section{G. CONTRIBUTOR'S REPRESENTATIONS}

The Contributor represents that the Contribution is the Contributor's original work. If the Contribution was prepared jointly, the Contributor agrees to inform the coContributors of the terms of this Agreement and to obtain their signature(s) to this Agreement or their written permission to sign on their behalf. The Contribution is submitted only to this Journal and has not been published before, except for "preprints" as permitted above. (If excerpts from copyrighted works owned by third parties are included, the Contributor will obtain written permission from the copyright owners for all uses as set forth in Wiley's permissions form or in the Journal's Instructions for Contributors, and show credit to the sources in the Contribution.) The Contributor also warrants that the Contribution contains no libelous or unlawful statements, does not infringe on the right or privacy of others, or contain material or instructions that might cause harm or injury.

Tick one box and fill in the appropriate section before returning the original signed copy to the Publisher

\section{Contributor-owned work}

Contributor's signature Date

Type or print name and title

Co-contributor's signature Date

Type or print name and title

\section{Attach additional signature page as necessary}

Company/Institution-owned work (made-for-

hire in the course of employment)

Contributor's signature

Type or print name and title

Company or Institution

(Employer-for Hire)

Authorised signature of Employer

Date

Type or print name and title

\section{US Government work}

Note to US Government Employees

A Contribution prepared by a US federal government employee as part of the employee's official duties, or which is an official US Government publication is called a "US Government work", and is in the public domain in the United States. In such case, the employee may cross out paragraph A1 but must sign and return this Agreement. If the Contribution was not prepared as part of the employee's duties or is not an official US Government publication, it is not a US Government work.

\section{UK Government work (Crown Copyright)}

Note to UK Government Employees

The rights in a Contribution by an employee of a UK Government department, agency or other Crown body as part of his/her official duties, or which is an official government publication, belong to the Crown. In such case, the Publisher will forward the relevant form to the Employee for signature. 


\section{WILEY AUTHOR DISCOUNT CARD}

As a highly valued contributor to Wiley's publications, we would like to show our appreciation to you by offering a unique $\mathbf{2 5 \%}$ discount off the published price of any of our books*.

To take advantage of this offer, all you need to do is apply for the Wiley Author Discount Card by completing the attached form and returning it to us at the following address:

The Database Group

John Wiley \& Sons Ltd

The Atrium

Southern Gate

Chichester

West Sussex P019 8SQ

UK

In the meantime, whenever you order books direct from us, simply quote promotional code S001W to take advantage of the $25 \%$ discount.

The newest and quickest way to order your books from us is via our new European website at:

\section{http://www.wileyeurope.com}

Key benefits to using the site and ordering online include:

- $\quad$ Real-time SECURE on-line ordering

- The most up-to-date search functionality to make browsing the catalogue easier

- Dedicated Author resource centre

- E-mail a friend

- $\quad$ Easy to use navigation

- Regular special offers

- $\quad$ Sign up for subject orientated e-mail alerts

So take advantage of this great offer, return your completed form today to receive your discount card.

Yours sincerely,

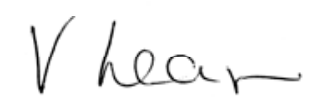

Verity Leaver

E-marketing and Database Manager 


\section{REGISTRATION FORM FOR 25\% BOOK DISCOUNT CARD}

To enjoy your special discount, tell us your areas of interest and you will receive relevant catalogues or leaflets from which to select your books. Please indicate your specific subject areas below.

Accounting

- Public

- Corporate

\section{Chemistry}

- Analytical

- Industrial/Safety

- Organic

- Inorganic

- Polymer

- Spectroscopy

Encyclopedia/Reference

- Business/Finance

- Life Sciences

- Medical Sciences

- Physical Sciences

- Technology

\section{Earth \& Environmental Science}

Hospitality

\section{Genetics}

- Bioinformatics/Computational Biology

- Proteomics

- Genomics

- Gene Mapping

- Clinical Genetics

\section{Medical Science}

- Cardiovascular

- Diabetes

- Endocrinology

- Imaging

- Obstetrics/Gynaecology

- Oncology

- Pharmacology

- Psychiatry

Non-Profit

\section{Architecture}

Business/Management

Computer Science

- Database/Data Warehouse

- Internet Business

- Networking

- Programming/Software Development

- Object Technology

Engineering

- Civil

- Communications Technology

- Electronic

- Environmental

- Industrial

- Mechanical

Finance/Investing

- Economics

- Institutional

- Personal Finance

Life Science

Landscape Architecture

Mathematics/Statistics

Manufacturing

Material Science

Psychology

- Clinical

- Forensic

- Social \& Personality

- Health \& Sport

- Cognitive

- Organizational

- Developmental and Special Ed

- Child Welfare

- Self-Help

Physics/Physical Science 
SIGNATURE:

PLEASE COMPLETE THE FOLLOWING DETAILS IN BLOCK CAPITALS:

TITLE AND NAME: (e.g. Mr, Mrs, Dr)

JOB TITLE:

DEPARTMENT:

COMPANY/INSTITUTION:

ADDRESS:

TOWN/CITY:

COUNTY/STATE:

COUNTRY:

POSTCODE/ZIP CODE:

DAYTIME TEL:

FAX:

E-MAIL:

YOUR PERSONAL DATA

We, John Wiley \& Sons Ltd, will use the information you have provided to fulfil your request. In addition, we would like to:

1. Use your information to keep you informed by post, e-mail or telephone of titles and offers of interest to you and available from us or other Wiley Group companies worldwide, and may supply your details to members of the Wiley Group for this purpose.

[ ] Please tick the box if you do not wish to receive this information

2. Share your information with other carefully selected companies so that they may contact you by post, fax or e-mail with details of titles and offers that may be of interest to you.

[ ] Please tick the box if you do not wish to receive this information.

If, at any time, you wish to stop receiving information, please contact the Database Group (databasegroup@wiley.co.uk) at John Wiley \& Sons Ltd, The Atrium, Southern Gate, Chichester, West Sussex PO19 8SQ, UK.

\section{E-MAIL ALERTING SERVICE}

We offer an information service on our product ranges via e-mail. If you do not wish to receive information and offers from John Wiley companies worldwide via e-mail, please tick the box [ ].

This offer is exclusive to Wiley Authors, Editors, Contributors and Editorial Board Members in acquiring books (excluding encyclopaedias and major reference works) for their personal use. There should be no resale through any channel. The offer is subject to stock availability and may not be applied retrospectively. This entitlement cannot be used in conjunction with any other special offer. Wiley reserves the right to vary the terms of the offer at any time.

Ref: S001W 